

\section{Disclaimer}

This report was prepared as an account of work sponsored by an agency of the United States Government. Neither the United States Government nor any agency thereof, nor any of their employees, makes any warranty, express or implied, or assumes any legal liability or responsibility for the accuracy, completeness, or usefulness of any information, apparatus, product, or process disclosed, or represents that its use would not infringe privately owned rights. Reference herein to any specific commercial product, process, or service by trade name, trademark, manufacturer, or otherwise, does not necessarily constitute or imply its endorsement, recommendation, or favoring by the United States Government or any agency thereof. The views and opinions of authors expressed herein do not necessarily state or reflect those of the United States Government or any agency thereof. 


\title{
Estimates of Fermilab Tevatron Collider Performance
}

\author{
G. Dugan \\ Fermilab \\ August 30, 1991
}

\section{Introduction}

This paper describes a model which has been used to estimate the average luminosity performance of the Tevatron collider. In the model, the average luminosity is related quantitatively to various performance parameters of the Fermilab Tevatron collider complex. The model is useful in allowing estimates to be developed for the improvements in average collider luminosity to be expected from changes in the fundamental performance parameters as a result of upgrades to various parts of the accelerator complex.

\section{Definitions}

Table 1 presents the definitions of the parameters used in this model.

Table 1: Parameter definitions and units

\begin{tabular}{|l|l|l|}
\hline Parameter & Description & Units \\
\hline $\mathrm{B}$ & Number of bunches in the collider & \\
\hline$\varepsilon_{\mathrm{T}}$ & $\begin{array}{l}\text { 95\% invariant transverse proton } \\
\text { emittance at Tevatron low-beta } \\
\text { (assumed equal in both planes) }\end{array}$ & $\pi \mathrm{mm}$-mrad \\
\hline $\bar{\varepsilon}_{\mathrm{T}}$ & $\begin{array}{l}\text { 95\% invariant transverse antiproton } \\
\text { emittance at Tevatron low-beta } \\
\text { (assumed equal in. both planes) }\end{array}$ & $\pi \mathrm{mm}$-mrad \\
\hline$\varepsilon_{\mathrm{T}}^{\mathrm{a}}$ & $\begin{array}{l}\text { Average 95\% invariant transverse beam } \\
\text { emittance at Tevatron low-beta } \\
\text { (assumed equal in both planes) }\end{array}$ & $\pi \mathrm{mm}$-mrad \\
\hline$\tau$ & Luminosity lifetime & hours \\
\hline$\beta^{*}$ & $\begin{array}{l}\text { beta-function at the Tevatron IP at full } \\
\text { energy }\end{array}$ & $\mathrm{m}$ \\
\hline $\mathrm{n}_{\mathrm{T}}$ & $\begin{array}{l}\text { Number of protons/bunch at Tevatron } \\
\text { low-beta }\end{array}$ & $10^{10}$ \\
\hline$\overline{\mathrm{N}}_{\mathrm{T}}$ & $\begin{array}{l}\text { Total number of antiprotons at } \\
\text { Tevatron low-beta }\end{array}$ & $10^{10}$ \\
\hline
\end{tabular}




\begin{tabular}{|c|c|c|}
\hline $\bar{Y}$ & $\begin{array}{l}\text { Antiproton yield: antiprotons' stacked } \\
\text { into the Accumulator core per } 120 \mathrm{GeV} \\
\text { proton on the antiproton production } \\
\text { target }\end{array}$ & $10^{-6}$ \\
\hline $\bar{P}$ & $\begin{array}{l}\text { Number of } 120 \mathrm{GeV} \text { protons on the } \\
\text { antiproton production target per Main } \\
\text { Ring cycle }\end{array}$ & $10^{12}$ \\
\hline $\mathrm{C}$ & Rate of Main Ring targeting cycles/sec & $\mathrm{Hz}$ \\
\hline$\overline{\mathrm{N}}_{\mathrm{A}}$ & $\begin{array}{l}\text { Number of antiprotons in the } \\
\text { Accumulator core }\end{array}$ & $10^{10}$ \\
\hline$\overline{\mathrm{N}}_{\mathrm{A}}^{\max }$ & $\begin{array}{l}\text { Maximum number of antiprotons in the } \\
\text { Accumulator core }\end{array}$ & $10^{10}$ \\
\hline $\bar{R}$ & Antiproton stacking rate & $10^{10 / \mathrm{hr}}$ \\
\hline$\overline{\varepsilon_{A}}$ & $\begin{array}{l}95 \% \text { invariant transverse antiproton } \\
\text { emittance at the Accumulator core } \\
\text { (assumed equal in both planes) }\end{array}$ & $\pi \mathrm{mm}$-mrad \\
\hline$\varepsilon_{B}$ & $\begin{array}{l}95 \% \text { invariant transverse proton } \\
\text { emittance from the Booster (assumed } \\
\text { equal in both planes) }\end{array}$ & $\pi \mathrm{mm}-\mathrm{mrad}$ \\
\hline$\Delta \varepsilon$ & $\begin{array}{l}\text { Increase in the } 95 \% \text { invariant transverse } \\
\text { proton emittance from the Booster to } \\
\text { Tevatron low-beta (assumed equal in } \\
\text { both planes) }\end{array}$ & $\pi \mathrm{mm}-\mathrm{mrad}$ \\
\hline$\Delta \bar{\varepsilon}$ & $\begin{array}{l}\text { Increase in the } 95 \% \text { invariant transverse } \\
\text { antiproton emittance during transfer } \\
\text { from the Accumulator core to Tevatron } \\
\text { low-beta (assumed equal in both planes) }\end{array}$ & $\pi \mathrm{mm}-\mathrm{mrad}$ \\
\hline $\mathrm{t}$ & time in the collider cycle & $\mathrm{hr}$ \\
\hline$T_{S}$ & Setup time & $\mathrm{hr}$ \\
\hline$T_{g}$ & Quiet time & $\mathrm{hr}$ \\
\hline $\mathrm{T}$ & Stacking time & $\overline{h r}$ \\
\hline $\mathbf{L}_{0}$ & Initial lurninosity & $10^{30} / \mathrm{cm}^{2} / \mathrm{sec}$ \\
\hline$\overline{L_{a}}$ & Average luminosity & $\mathrm{pb}^{-1 / \text { week }}$ \\
\hline $\mathrm{r}$ & $\begin{array}{l}\text { Efficiency of antiproton transfer, } \\
\text { Accumulator core to Tevatron-low-beta }\end{array}$ & $\%$ \\
\hline $\mathrm{r}_{\mathrm{A}}$ & $\begin{array}{l}\text { Efficiency of antiproton transfer, } \\
\text { Accumulator core to Main Ring }\end{array}$ & $\%$ \\
\hline$\overline{r_{M}}$ & $\begin{array}{l}\text { Efficiency of antiproton transfer, Main } \\
\text { Ring to Tevatron, } 150 \mathrm{GeV}\end{array}$ & $\%$ \\
\hline $\mathrm{r}_{\mathrm{T}}$ & $\begin{array}{l}\text { Efficiency of antiproton transfer, } \\
\text { Tevatron, } 150 \mathrm{GeV} \text { to Tevatron-low-beta }\end{array}$ & $\%$ \\
\hline $\mathrm{f}$ & Unstacking fraction & $\%$ \\
\hline $\mathrm{f}_{\mathrm{rev}}$ & \begin{tabular}{|l} 
Tevatron beam revolution frequency \\
\end{tabular} & $\mathrm{Hz}$ \\
\hline
\end{tabular}




\begin{tabular}{|c|c|c|}
\hline$\sqrt{s_{b l}}$ & $\begin{array}{l}\text { Luminosity finite-bunch-length } \\
\text { correction factor }\end{array}$ & $\%$ \\
\hline gl & Tevatron Collider operational efficiency & $\%$ \\
\hline$g_{s}$ & Antiproton Source stacking efficiency & $\%$ \\
\hline$\rho(\kappa)$ & $\begin{array}{l}\text { Antiproton longitudinal density in the } \\
\text { Accumulator core }\end{array}$ & $10^{10} / \mathrm{eV}-\mathrm{sec}$ \\
\hline $\bar{\kappa}$ & $\begin{array}{l}\text { Antiproton longitudinal emittance in } \\
\text { the Accumulator core }\end{array}$ & eV-sec \\
\hline$\sigma_{K}$ & $\begin{array}{l}\text { rms antiproton longitudinal emittance } \\
\text { in the Accumulator core }\end{array}$ & eV-sec \\
\hline$\kappa_{B}$ & $\begin{array}{l}\text { Antiproton longitudinal emittance } \\
\text { unstacked per bunch }\end{array}$ & eV-sec \\
\hline po & $\begin{array}{l}\text { Peak antiproton longitudinal density in } \\
\text { the Accumulator core }\end{array}$ & $10^{10} / \mathrm{eV}-\mathrm{sec}$ \\
\hline$\overline{\mathrm{N}}_{\mathrm{A}}^{\text {unstack }}$ & $\begin{array}{l}\text { Number of antiprotons unstacked from } \\
\text { the Accumulator core }\end{array}$ & $10^{10}$ \\
\hline$g_{u}$ & Unstacking efficiency & $\%$ \\
\hline$\alpha_{t}$ & $\begin{array}{l}\text { Intercept parameter describing } 95 \% \\
\text { invariant antiproton transverse density } \\
\text { vs. stack size dependence }\end{array}$ & $\pi$ mm-mrad \\
\hline$\overline{\beta_{t}}$ & $\begin{array}{l}\text { Slope parameter describing } 95 \% \\
\text { invariant antiproton transverse density } \\
\text { vs. stack size dependence }\end{array}$ & $\pi \mathrm{mm}-\mathrm{mrad} / 10^{10}$ \\
\hline$\gamma_{t}$ & $\begin{array}{l}\text { Quadratic parameter describing } 95 \% \\
\text { invariant antiproton transverse density } \\
\text { vs. stack size dependence }\end{array}$ & $\pi \mathrm{mm}-\mathrm{mrad} /\left(10^{10}\right)^{2}$ \\
\hline$\alpha_{1}$ & $\begin{array}{l}\begin{array}{l}\text { Intercept parameter describing peak } \\
\text { antiproton longitudinal density vs. stack } \\
\text { size dependence }\end{array} \\
\end{array}$ & eV-sec \\
\hline$\beta_{1}$ & $\begin{array}{l}\text { Slope parameter describing peak } \\
\text { antiproton longitudinal density vs. stack } \\
\text { size dependence }\end{array}$ & $\mathrm{eV}-\sec / 10^{10}$ \\
\hline$\gamma_{1}$ & $\begin{array}{l}\text { Quadratic parameter describing peak } \\
\text { antiproton longitudinal density vs. stack } \\
\text { size dependence }\end{array}$ & $e V-\sec /\left(10^{10}\right)^{2}$ \\
\hline$\alpha_{r}$ & \begin{tabular}{|l|} 
Intercept parameter describing \\
antiproton transfer efficiency into the \\
Main Ring vs. transverse emittance \\
\end{tabular} & $\%$ \\
\hline$\beta_{r}$ & $\begin{array}{l}\text { Slope parameter describing antiproton } \\
\text { transfer efficiency into the Main Ring } \\
\text { vs. transverse emittance }\end{array}$ & $\% / \pi \mathrm{mm}-\mathrm{nizad}$ \\
\hline$\gamma_{\mathrm{r}}$ & $\begin{array}{l}\text { Quadratic parameter describing } \\
\text { antiproton transfer efficiency into the } \\
\text { Main Ring vs. transverse emittance }\end{array}$ & $\% /(\pi \mathrm{mm}-\mathrm{mrad})^{2}$ \\
\hline
\end{tabular}




\begin{tabular}{|l|l|l|}
\hline$\gamma$ & Relativistic gammia at Tevatron IP & \\
\hline $\mathrm{F}_{\mathrm{t}}$ & $\begin{array}{l}\text { Fraction of the Accumulator core lost } \\
\text { transversely per hour }\end{array}$ & $\% / \mathrm{hr}$ \\
\hline $\mathrm{F}_{\mathrm{l}}$ & $\begin{array}{l}\text { Total number of antiprotons lost } \\
\text { longitudinally from the Accumulator } \\
\text { core per hour }\end{array}$ & $10^{10 / \mathrm{hr}}$ \\
\hline$\tau_{\mathrm{gas}}$ & $\begin{array}{l}\text { Accumulator core lifetime due to } \\
\text { interactions with the residual gas }\end{array}$ & $\mathrm{hr}$ \\
\hline$\langle\mathrm{R}\rangle$ & $\begin{array}{l}\text { "Operational" antiproton source } \\
\text { stacking rate }\end{array}$ & $10^{10 / \mathrm{hr}}$ \\
\hline$\left\langle\mathrm{L}_{\mathrm{a}}\right\rangle$ & "Operational" average luminosity & $\mathrm{pb}^{-1 / \text { week }}$ \\
\hline
\end{tabular}

\section{Model Pielationships}

\subsection{General remarks}

This model addresses only collider operation when cyclic equilibrium of the basic collider cycle has been attained. The model does not apply to transient situations in which one is starting operation from the $\bar{N}_{A}=0$ situation. However, in the long run transient situations would not be expected to be important unless the mean time between stark losses of the antiproton source due to failures was comparable to or smaller than the cyclic equilibrium period $\mathrm{T}+\mathrm{T}_{\mathrm{s}}+\mathrm{T}_{\mathrm{q}}$. This is not the case for the Fermilab antiproton source.

The cyclic equilibrium situation is represented in fig 1 :

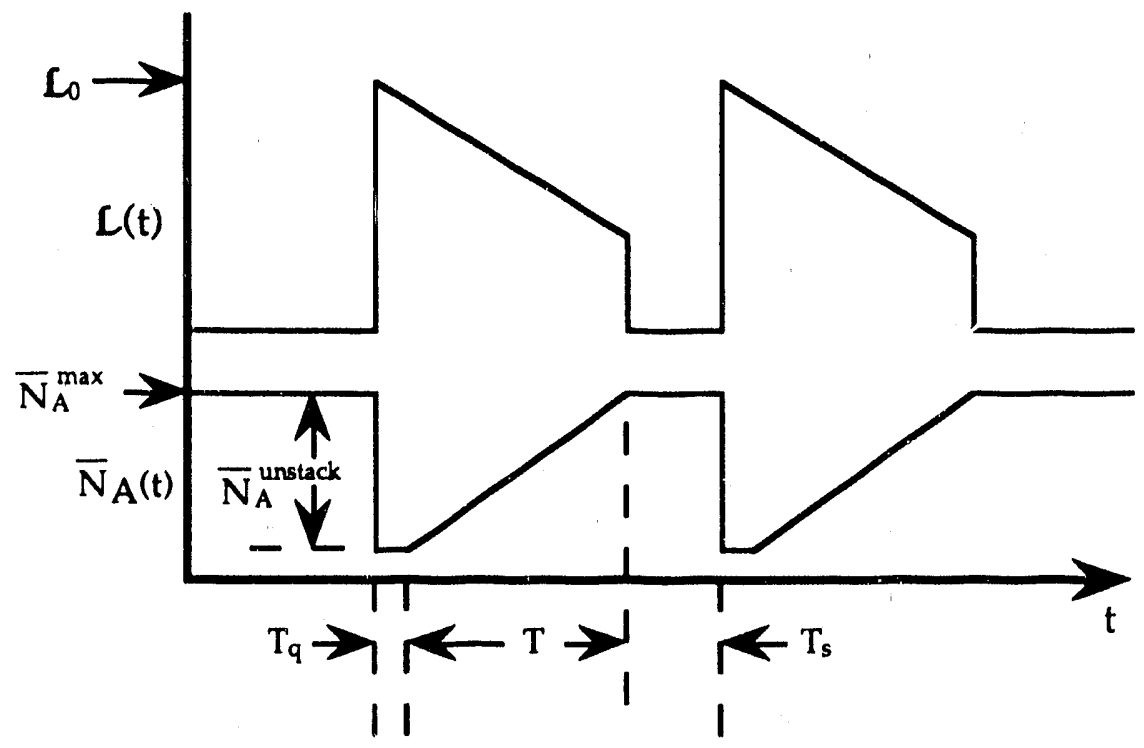

Figure 1: Cyclic equilibrium for collider operation 
During the period $T_{S}$ (the setup time), antiproton stacking does not occur, and preparations are made for loading the collider from the existing stack of $\overline{\mathrm{N}}_{\mathrm{A}}^{\text {max }}$ antiprotons. At the end of the setup time, the collider is loaded to an initial luminosity $\mathcal{L}_{0}$, with the removal from the Accumulator core of $\overline{\mathrm{N}}_{\mathrm{A}}^{\text {unstack }}=\mathrm{f} \overline{\mathrm{N}}_{\mathrm{A}}^{\max }$ antiprotons, where $\mathrm{f}$ (the unstacking fraction) is the fraction of the core removed. After a time $T_{q}$ (quiet time: time to restore the antiproton source to the stacking mode), antiproton stacking resumes for a period of time $\mathrm{T}$, after which the basic collider cycle repeats itself.

For the cyclic equilibrium situation shown in fig. 1, the average luminosity is given (in the units of Table 1) by

$$
\begin{aligned}
\mathcal{L}_{a} & =\left[0.6048 \mathcal{L}_{0} /\left(T_{s}+T_{q}+T\right)\right] \int_{0}^{T+T_{q}} \exp (-t / \tau) d t \\
& =0.6048 L_{0} \tau\left[1-\exp \left\{-\left(T+T_{q}\right) / \tau\right\}\right] /\left(T_{s}+T_{q}+T\right)
\end{aligned}
$$

assuming the luminosity lifetime is independent of time. This assumption is in fact not realized in the Tevatron collider, but will be made in this model for the sake of simplicity. The luminosity lifetime increases during a store, but not by more than a factor of two.

During the stacking time $T$, the Accumulator core must be restored to $\bar{N}_{A}^{\max }$. Since the antiproton stacking rate $R=d \bar{N}_{A} / d t$ is in general a function of $\overline{\mathrm{N}}_{\mathrm{A}}$, the stacking time $\mathrm{T}$ is

$$
\mathrm{T}=\int_{(1-\mathrm{f}) \overline{\mathrm{N}}_{\mathrm{A}}^{\max }}^{\overline{\mathrm{N}}_{\mathrm{A}}^{\max }} \mathrm{d} \overline{\mathrm{N}}_{\mathrm{A}} / \mathrm{R}\left(\overline{\mathrm{N}}_{\mathrm{A}}\right)
$$

Given an explicit parametric dependence of $R$ on $\bar{N}_{A}$, equation 2 can be solved to give $T$ as a function of $f, \bar{N}_{A}^{\max }$, and the parameters of $R$; the result can be substituted into equation (1) to give the average luminosity as a function of $f, \bar{N}_{A}^{\max }$, and the parameters of $R$. In addition (see 3.3, below), the initial luminosity $\mathcal{L}_{0}$ is a function of $f, \bar{N}_{A}^{\max }$, and several other parameters.

\subsection{Optimization of the average luminosity}

With the actual form of $R\left(\bar{N}_{A}\right)$ and $\mathcal{L}_{0}$ as described in sections 3.3 and 3.4 below, the average luminosity $\mathcal{L}_{a}$ (and, of course, $\bar{N}_{A}^{-\max }$ ) increases with 
stacking time $T$ to a maximum; after the maximum is reached, $L_{a}$ decreases (although $\bar{N}_{A}^{\max }$ continues to increase). The general form of this dependence is illustrated in fig. 2.

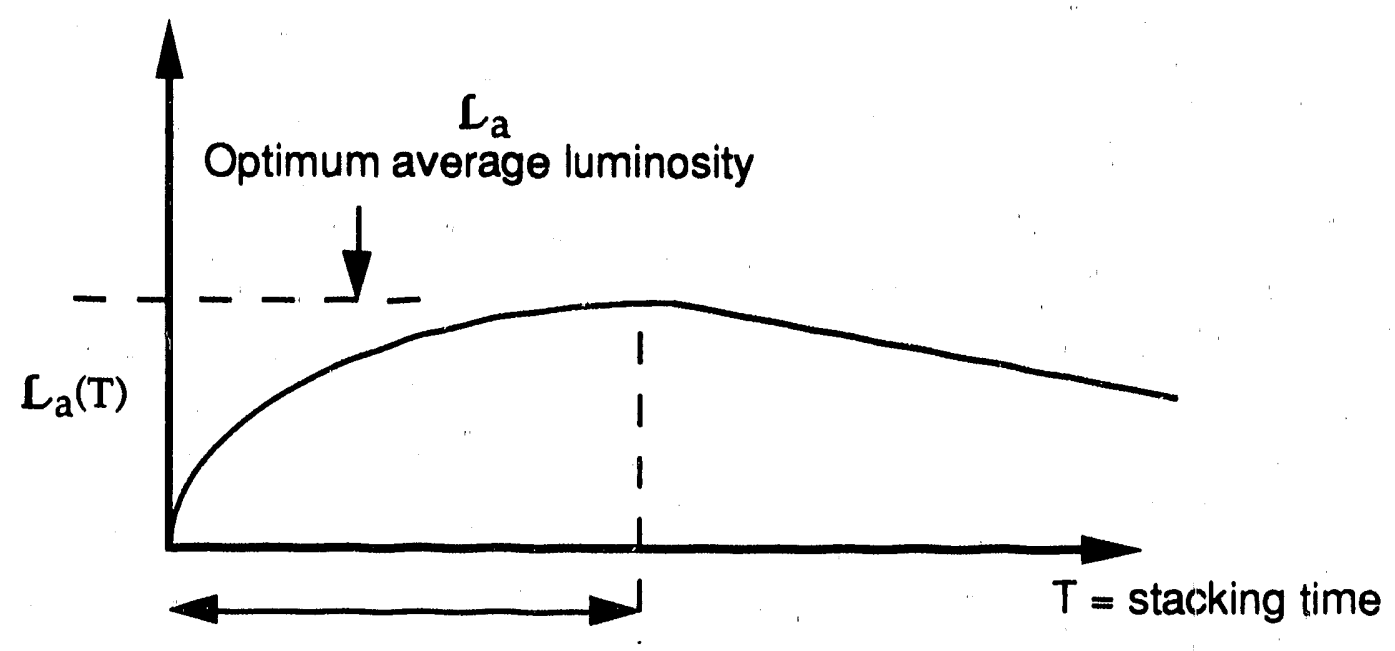

Optimum stacking time

Figure 2: General behavior of the average luminosity as a function of the stacking time

The value of $\mathrm{T}$ at the maximum is the "optimum stacking time", and the corresponding value of $\overline{\mathrm{N}}_{A}^{\max }$ is the "optimum maximum stack". The optimum stacking time (plus $\mathrm{T}_{\mathrm{q}}$ ) is also the optimum storage time. Operation of the collider in the cyclic equilibrium mode with $T$ equal to the optimum stacking time will maximize the average (and hence integrated) luminosity. The model calculation determines this optimum stacking tirne, optimum maximum stack and the corresponding value of the average luminosity, as a function of the other parameters in the model.

The full calculation computes $\mathrm{T}$ by numerical integration of equation (2) using the form of $R\left(\bar{N}_{A}\right)$ given below in section 3.4. However, it is useful to introduce a simplified approximation to $R\left(\overline{\mathrm{N}}_{\mathrm{A}}\right)$ in order to illustrate severai features of the model. This simplified approximation is:

$$
\begin{aligned}
& R\left(\bar{N}_{A}\right)=R \text { for } \bar{N}_{A} \leq \bar{N}_{A}^{\max }, \\
& R\left(\bar{N}_{A}\right)=0 \text { for } \bar{N}_{A}>\bar{N}_{A}^{\text {max }},
\end{aligned}
$$

in which $\overline{\mathrm{N}}_{A}^{\text {max }}$ is a fixed quantity, representing the maximum stack size which the Accumulator will tolerate; for stack sizes below this, the stacking 
rate is the constant $R$, independent of $\bar{N}_{A}$. Collider operation in cyclic equilibrium is assumed to consist of cycles in which one stacks in the Accumulator until $\overline{\mathrm{N}}_{\mathrm{A}}^{\max }$ is reached, after which a transfer occurs.

In this approximation, the stacking time $\mathrm{T}$ is given by

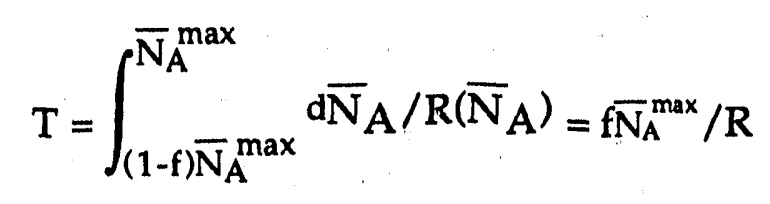

so that

$$
\mathbf{L}_{\mathrm{a}}=\mathbf{L}_{0} \tau\left\{1-\exp \left[-\left(\mathrm{f} \bar{N}_{A}^{\max } / \mathrm{R}+\mathrm{T}_{\mathrm{q}}\right) / \tau\right]\right\} /\left(\mathrm{T}_{\mathrm{S}}+\mathrm{T}_{\mathrm{q}}+\mathrm{f} \overline{\mathrm{N}}_{\mathrm{A}}^{\max } / \mathrm{R}\right)
$$

If $T_{S}$ and $T_{q}$ are small compared to $T$, then this simplifies to

$$
\mathfrak{L}_{\mathrm{a}}=\mathcal{L}_{0} \operatorname{R} \tau\left[1-\exp \left(-\overline{\mathrm{fN}}_{\mathrm{A}}^{\max } / \mathrm{R} \tau\right)\right] / \mathrm{f}_{\mathrm{A}}^{\max }
$$

As discussed in section 3.3 below,

$$
\mathbf{L}_{0} \propto \overline{\mathrm{N}}_{\mathrm{T}}, \text { and } \overline{\mathrm{N}}_{\mathrm{T}} \propto \mathrm{f} \overline{\mathrm{N}}_{\mathrm{A}}^{\max } ;
$$

thus,

$$
\mathrm{L}_{\mathrm{a}} \propto \mathrm{R} \tau\left[1-\exp \left(-\mathrm{f} \overline{\mathrm{N}}_{\mathrm{A}}^{\max } / \mathrm{R} \tau\right)\right]
$$

Two simple relations may be derived from this. The average luminosity may be written in terms of the parameter $x=f \bar{N}_{A}^{\max } / R \tau$, as

$$
L_{\mathrm{a}} \propto \mathrm{fN}_{\mathrm{A}}^{\max }[1-\exp (-\mathrm{x})] / \mathrm{x}
$$

The parameter $x$ is just the ratio of the time required to replenish the stack to the luminosity lifetime. This parameter is small if the luminosity lifetime is large compared to the time required to replenish the stack; this may result from a large stacking rate or a small stack maximum. In this situation, we have

$$
L_{\mathrm{a}} \propto \mathrm{f} \overline{\mathrm{N}}_{\mathrm{A}}^{\max }
$$

The average luminosity is independent of the stacking rate or the luminosity lifetime; it is limited by the stack maximum, and also depends directly on the unstacking fraction. 
The parameter $x$ is large if the luminosity lifetime is small compared to the time required to replenish the stack; this may result from a small stacking rate, or a small luminosity lifetime, together with a large stack maximum. In this case, we have that

$$
\mathbf{L}_{\mathbf{a}} \propto \mathbf{R} \tau
$$

The average luminosity is independent of the stack maximum and depends only on the product of the stacking rate and the luminosity lifetime. This situation may also result if the mean time between failures of the collider becomes small, since the role of the mean time between failures is essentially equivalent to that of the lurninosity lifetime.

\subsection{Initial luminosity}

The initial luminosity $\mathcal{L}_{0}$, using the units indicated above for all quantities, is given by:

$$
\begin{aligned}
& \mathcal{L}_{0}=6 \times 10^{-8} \mathrm{n}_{\mathrm{T}} \overline{\mathrm{N}}_{\mathrm{T}} \gamma \mathrm{f}_{\mathrm{rev}} \mathrm{s}_{\mathrm{bl}} / 4 \pi \beta^{*} \varepsilon_{\mathrm{T}}^{\mathrm{a}} \\
& =0.1616 \mathrm{n}_{\mathrm{T}} \overline{\mathrm{N}}_{\mathrm{T}} / \beta^{*} \varepsilon_{\mathrm{T}}^{\mathrm{a}},
\end{aligned}
$$

using $\mathrm{f}_{\mathrm{rev}}=47700 \mathrm{~Hz}, \gamma=959$ (for $900 \mathrm{GeV}$ operation), and $\mathrm{sbl}=0.74$ (appropriate for $\beta^{*}=0.5 \mathrm{~m}$ and a longitudinal rms bunch length of about 0.4 $\mathrm{m}$, which is roughly the case for all conditions studied with this model).

In this equation, we have

$$
\begin{aligned}
& \varepsilon_{\mathrm{T}}^{\mathrm{a}}=\left(\varepsilon_{\mathrm{T}}+\bar{\varepsilon}_{\mathrm{T}}\right) / 2, \text { and } \\
& \bar{\varepsilon}_{\mathrm{T}}=\bar{\varepsilon}_{\mathrm{A}}+\Delta \bar{\varepsilon}_{\text {, and }} \varepsilon_{\mathrm{T}}=\varepsilon_{\mathrm{B}}+\Delta \varepsilon
\end{aligned}
$$

Equation 13 expresses the emittance dilution which may occur to the antiprotons during antiproton transfer, and to the protons during transfer from the Booster to the Tevatron. $\bar{\varepsilon}_{A}$ depends on $\bar{N}_{A}^{\max }$, as described below. In this model, the proton transverse emittance $\varepsilon_{B}$ is fixed at $15 \pi \mathrm{mm}-\mathrm{mrad}$, and $\Delta \varepsilon$ is a parameter of the model.

We also have

$$
\overline{\mathrm{N}}_{\mathrm{T}}=\mathrm{f} \overline{\mathrm{N}}_{\mathrm{A}}^{\max } \mathbf{r}
$$

where

$$
r=r_{A} r_{M} r_{T}
$$


is the product of the three individual transfer efficiencies. The efficiency $r_{A}$ is a function of $\bar{\varepsilon}_{\mathrm{A}}$, because of aperture restrictions at Main Ring injection, and hence is also a function of $\bar{N}_{A}^{\max }$ (see section 3.7 below). The efficiencies $r_{M}$ and $\mathrm{r}_{\mathrm{T}}$ are taken to be independent of $\overline{\mathrm{N}}_{\mathrm{A}}^{\max }$. The unstacking fraction $\mathrm{f}$ is discussed below in section 3.5 .

Combining equations 11 through 15, we have for the initial luminosity

$$
L_{0}=0.3232 \mathrm{n}_{\mathrm{T}} \mathrm{f} \overline{\mathrm{N}}_{\mathrm{A}}^{\max } \mathrm{r}_{\mathrm{A}}\left(\overline{\mathrm{N}}_{\mathrm{A}}^{\max }\right) \mathrm{r}_{\mathrm{M}} \mathrm{r} / \beta^{*}\left[\varepsilon_{B}+\Delta \varepsilon+\bar{\varepsilon}_{A}\left(\bar{N}_{\mathrm{A}}^{\max }\right)+\Delta \bar{\varepsilon}\right]
$$

\subsection{Antiproton Source Stacking Rate}

The antiproton stacking rate, using the units indicated above for all quantities, is given by:

$$
R\left(\bar{N}_{A}\right)=d \bar{N}_{A} / d t=0.36 Y\left(\bar{N}_{A}\right) P C
$$

The dependence of the antiproton yield $X$ on the stack intensity $\bar{N}_{A}$ depends principally on the performance of the st $k$-tail and core cooling systems in the Accumulator, the size of the Accumulator aperture, and the quality of the Accumulator vacuum. In fact, the yield also depends on the cycle rate $C$, but this dependence has been ignored here, since it is not important for the dynamics of the model.

The calculation of the yield variation with $\overline{\mathrm{N}}_{\mathrm{A}}$ involves estimates of loss mechanisms from the Accumulator. There are fundamentally three ways in which particles may be lost from the core:

(1) Transverse losses: The core emittance is determined by the equilibrium between heating mechanisms (such as intrabeam scattering) and the core cooling systems. This equilibrium is such that the core transverse emittance grows (approximately linearly) with stack size. The actual dependence of $\bar{\varepsilon}_{A}$ on $\bar{N}_{A}$ is parameterized as a quadratic:

$$
\bar{\varepsilon}_{A}\left(\overline{\mathrm{N}}_{A}\right)=\alpha_{t}+\beta_{t} \bar{N}_{A}+\gamma_{t} \bar{N}_{A}{ }^{2}
$$

This parameterization has been taken from empirical data obtaining during the 1988-89 collider run. ${ }^{1}$ It represents the antiproton beam emittance in the cooled core, just prior to antiproton transfer, with the stack-tail system off. The actual core emittance during stacking, which is what is relevant here, is somewhat larger (see below).

As the core transverse emittance grows, beam may be scraped by the edges of the finite Accumulator aperture and be lost. The total fraction of the 
core lost by this mechanism per hour is denoted $F_{t}$; it depends on $\bar{N}_{A}$ through $\bar{\varepsilon}_{\mathrm{A}}$.

(2) Attenuation through interactions with the residual gas: this is an exponential loss with time constant $\tau_{\text {gas. }}$

(3) Longitudinal losses: at sufficiently high input fluxes to the stack-tail system, beam may be lost longitudinally, a process which depends on the intensity in the stack-tail, which in turn depends on the core intensity. The total longitudinal loss per hour is denoted $\mathrm{F}_{\mathrm{l}}$; it depends not only on $\overline{\mathrm{N}}_{\mathrm{A}}$, but also on the bandwidth of the stack-tail cooling system.

These three loss mechanisms together imply that the total change in the intensity of the Accumulator core with time is

$$
R=d \bar{N}_{A} / d t=0.36 Y_{0} P C-\bar{N}_{A} / \tau_{\text {gas }}-\bar{N}_{A} \cdot F_{t}\left(\bar{N}_{A}\right)-F_{l}\left(\bar{N}_{A}\right)
$$

where $Y_{0}=Y(0)$, the yield at $\bar{N}_{A}=0$. The first term on the RHS in equation 19 represents the flux entering the core due to antiproton production. The last three terms represent the three loss mechanisms described above. Combining equations 17 and 19 gives,

$$
\mathrm{Y}\left(\overline{\mathrm{N}}_{\mathrm{A}}\right)=\mathrm{Y}_{0}\left[1-\left\{\overline{\mathrm{N}}_{\mathrm{A}}\left[1 / \tau_{\text {gas }}+\mathrm{F}_{\mathrm{t}}\left(\overline{\mathrm{N}}_{\mathrm{A}}\right)\right]+\mathrm{F}_{\mathrm{l}}\left(\overline{\mathrm{N}}_{\mathrm{A}}\right)\right\} / 0.36 \mathrm{PC}\right]
$$

For the model calculation described in this paper, the function $F_{t}\left(\bar{\varepsilon}_{A}\right)$ has been computed numerically ${ }^{2}$; the result, for a $10 \pi \mathrm{mm}$-mrad aperture Accumulator, is shown in fig. 3. To obtain $F_{t}\left(\bar{N}_{A}\right)$, the transverse emittance $\bar{\varepsilon}_{A}$ has been related to $\bar{N}_{A}$ using equation 18 , except that the emittance has been multiplied by a factor $\mathrm{E}$ to account for the fact that the core transverse emittance during stacking is actually larger than during antiproton transfer(which is what equation 18 expresses) since imperfections in the stack tail system heat the core beam transversely.

The function $F_{1}\left(\bar{N}_{A}\right)$ has also been computed numerically, from a computer simulation of the stochastic stacking process ${ }^{2}$. It depends on the parameters of the Accumulator stack tail system, particularly the system bandwidth, and on the momentum spread of the beam injected from the Debuncher.

Figs. 4 through 8 show the results of calculations of $Y\left(\overline{\mathrm{N}}_{\mathrm{A}}\right)$ vs $\overline{\mathrm{N}}_{\mathrm{A}}$, for various sets of conditions appropriate to different phases of the Fermilab III upgrade. Table 2 details the conditions associated with each of the figures. 


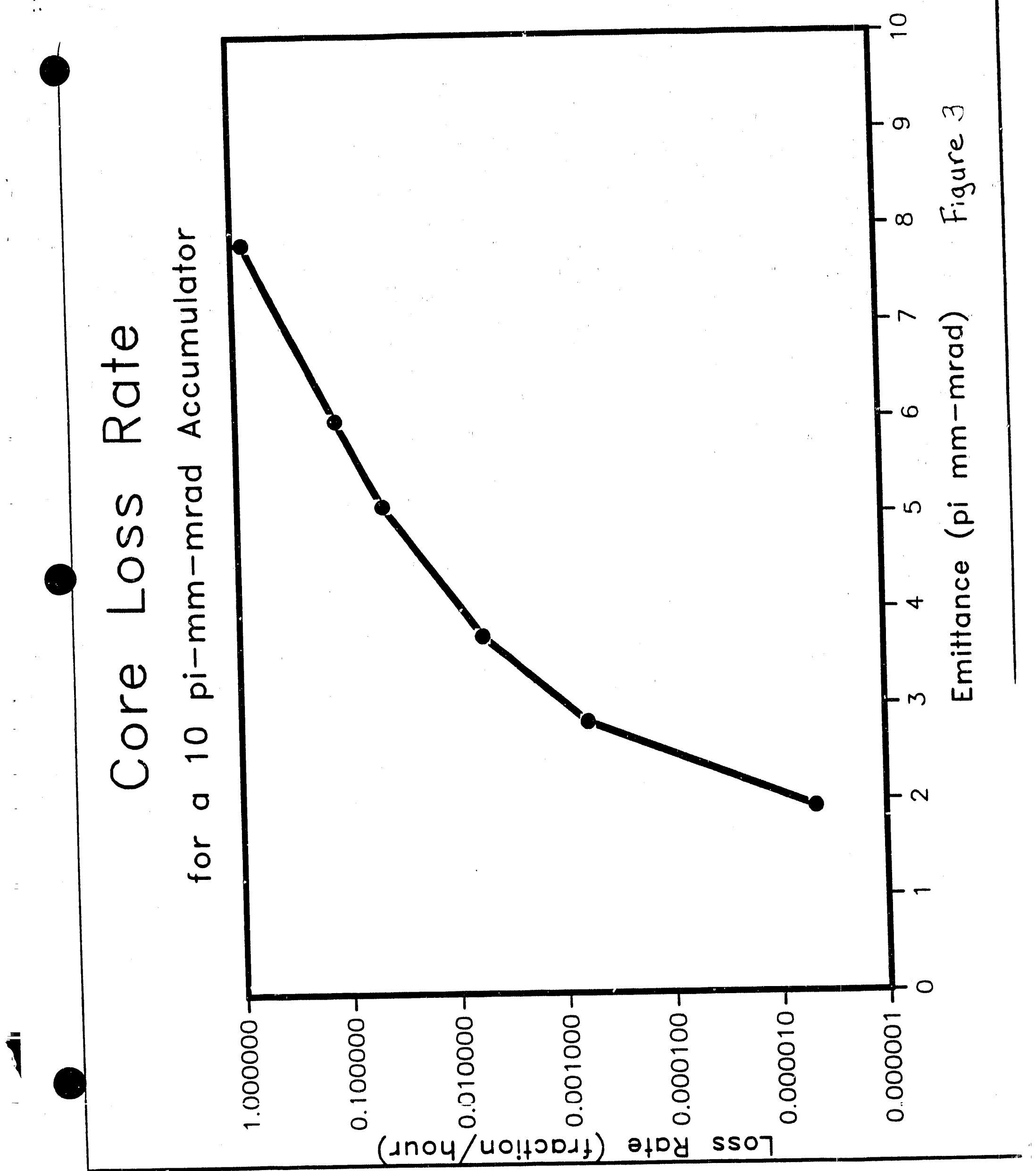




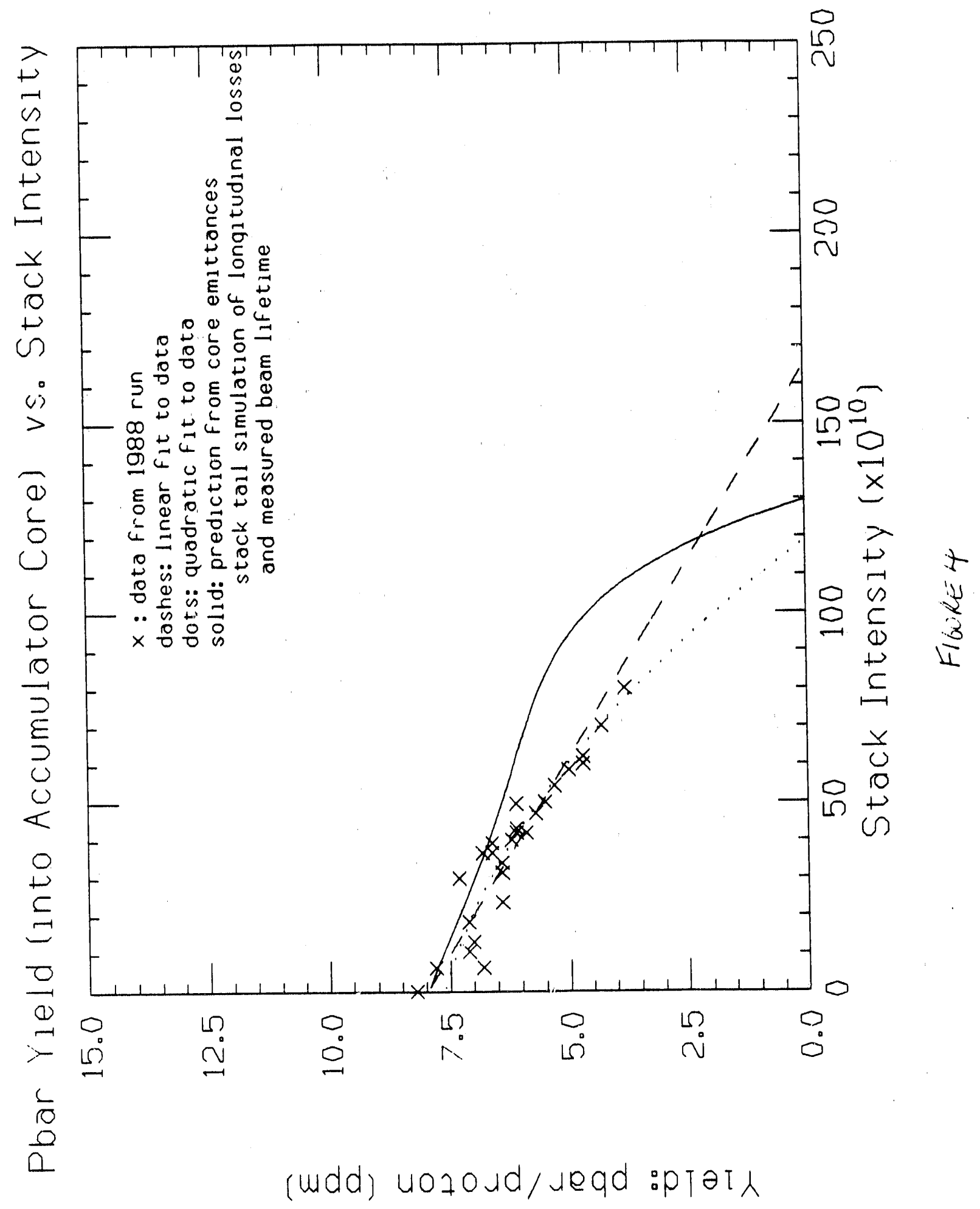




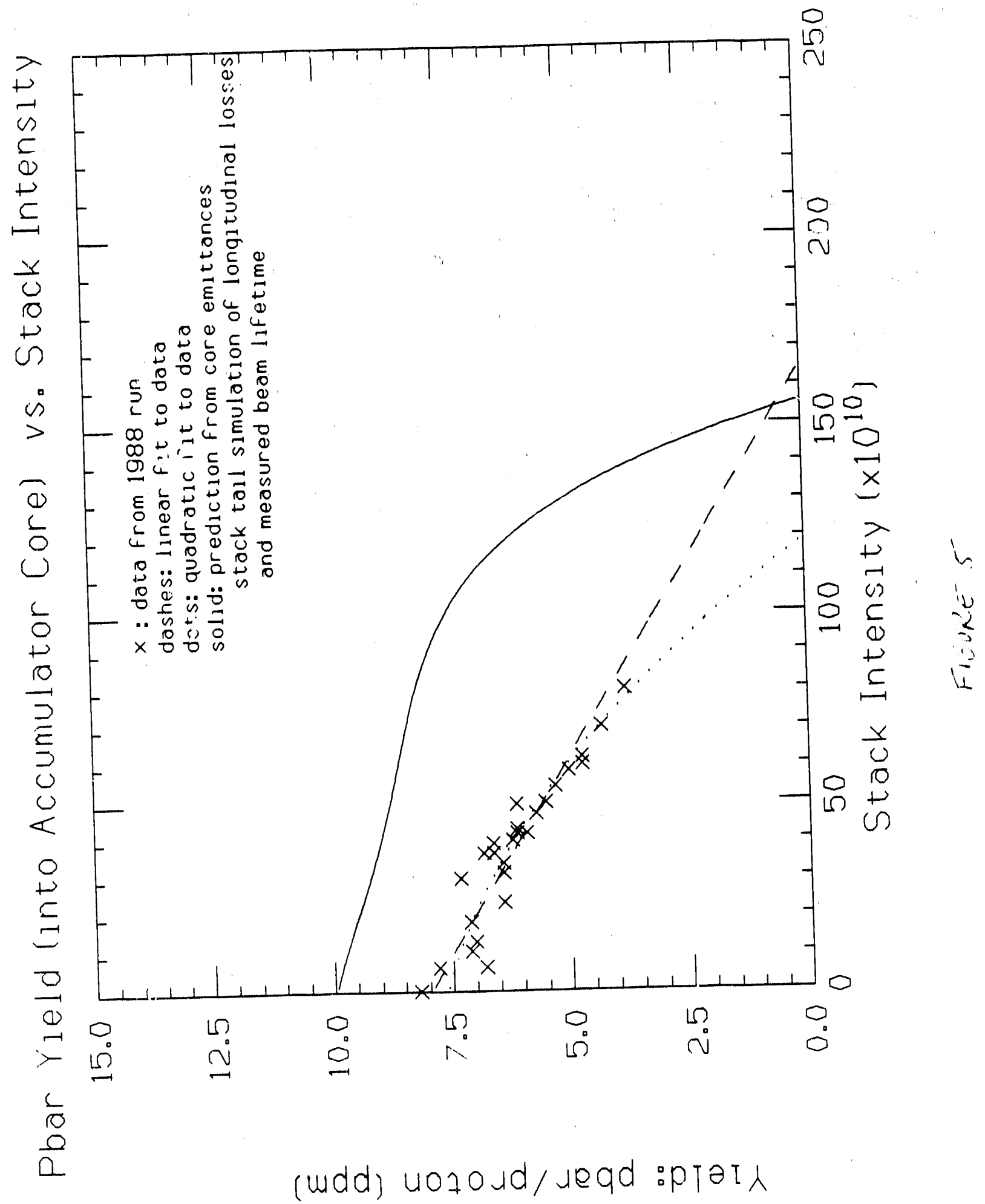




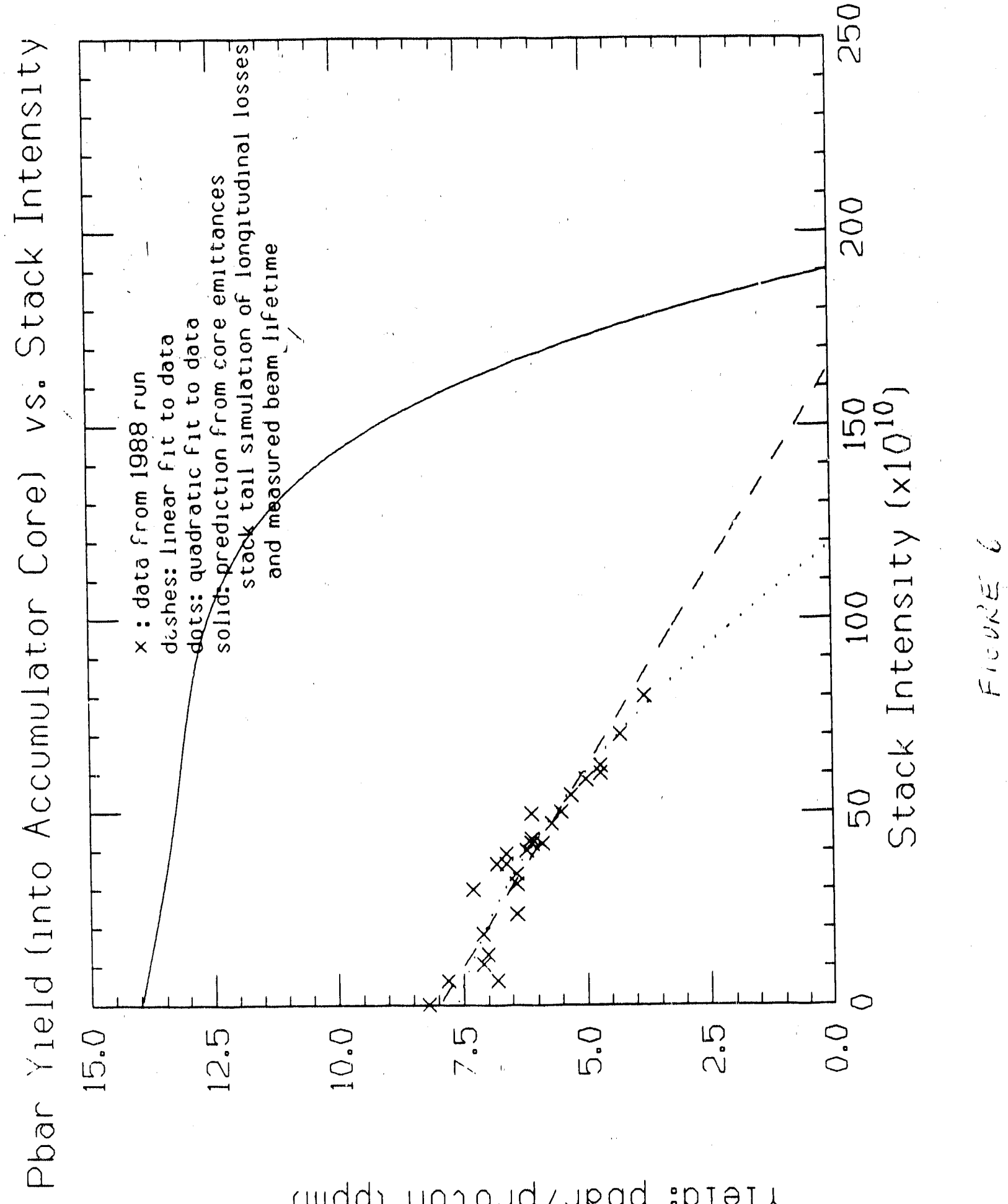

(udd) no10ud/ueqd:p广or人 


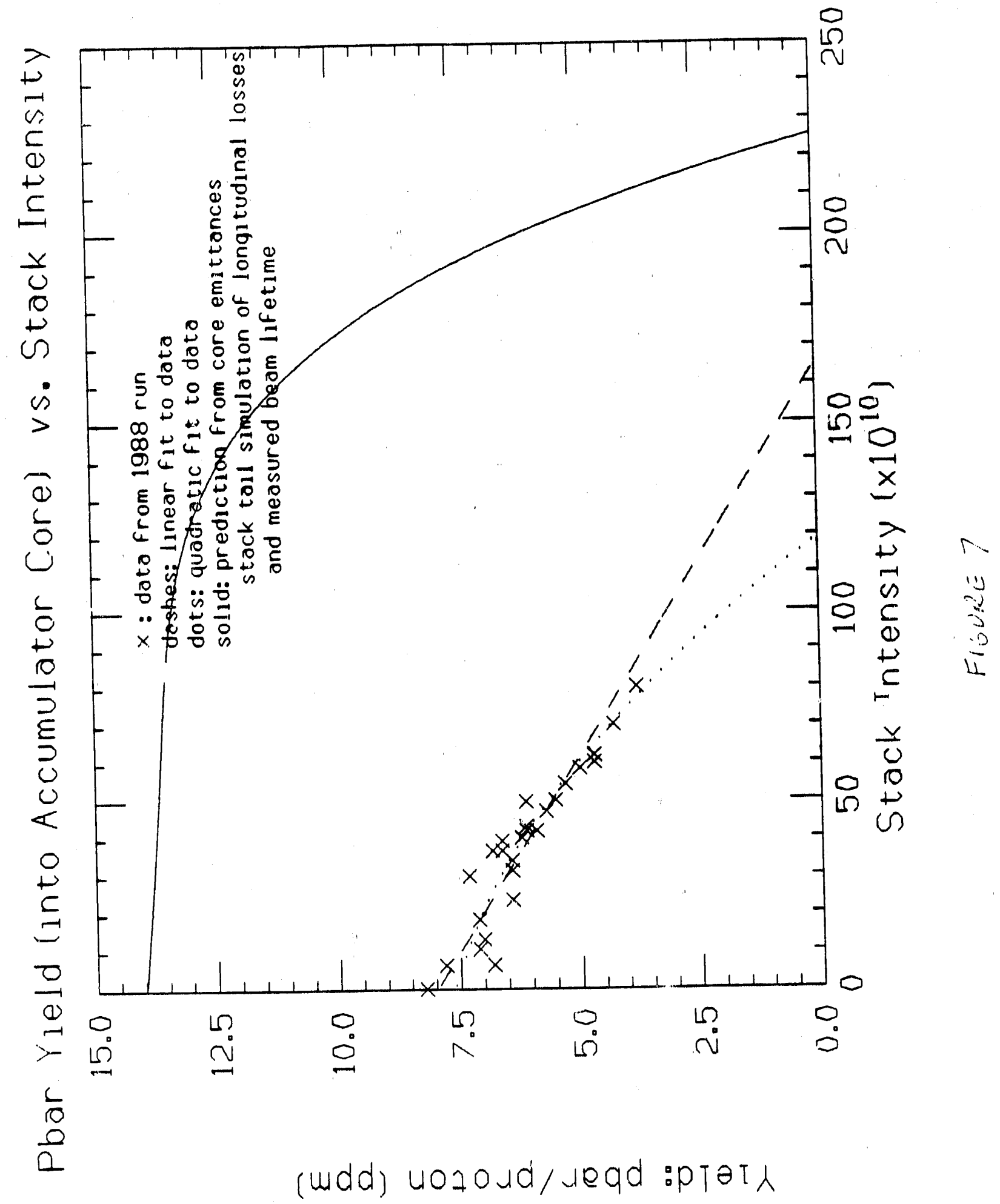




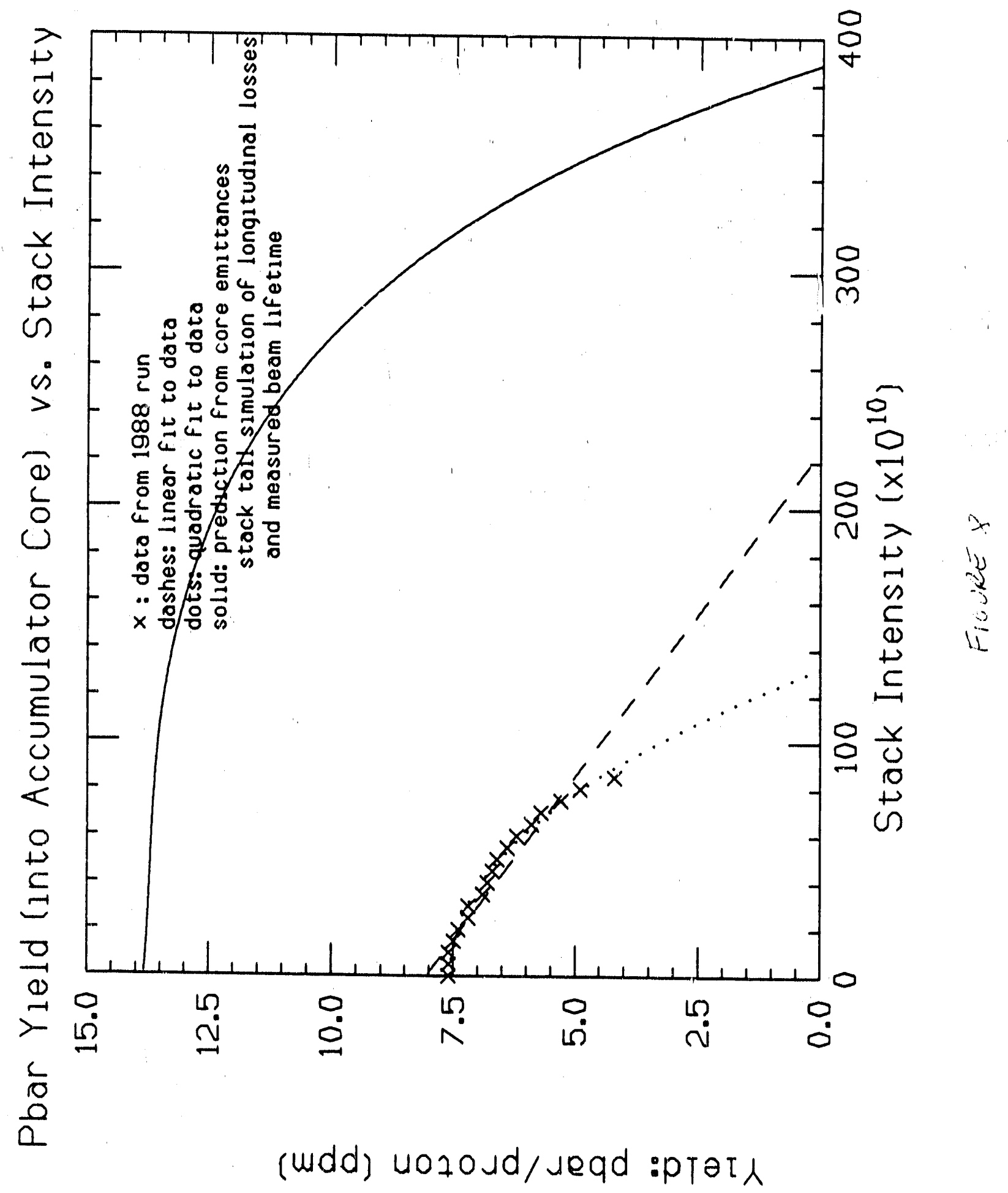



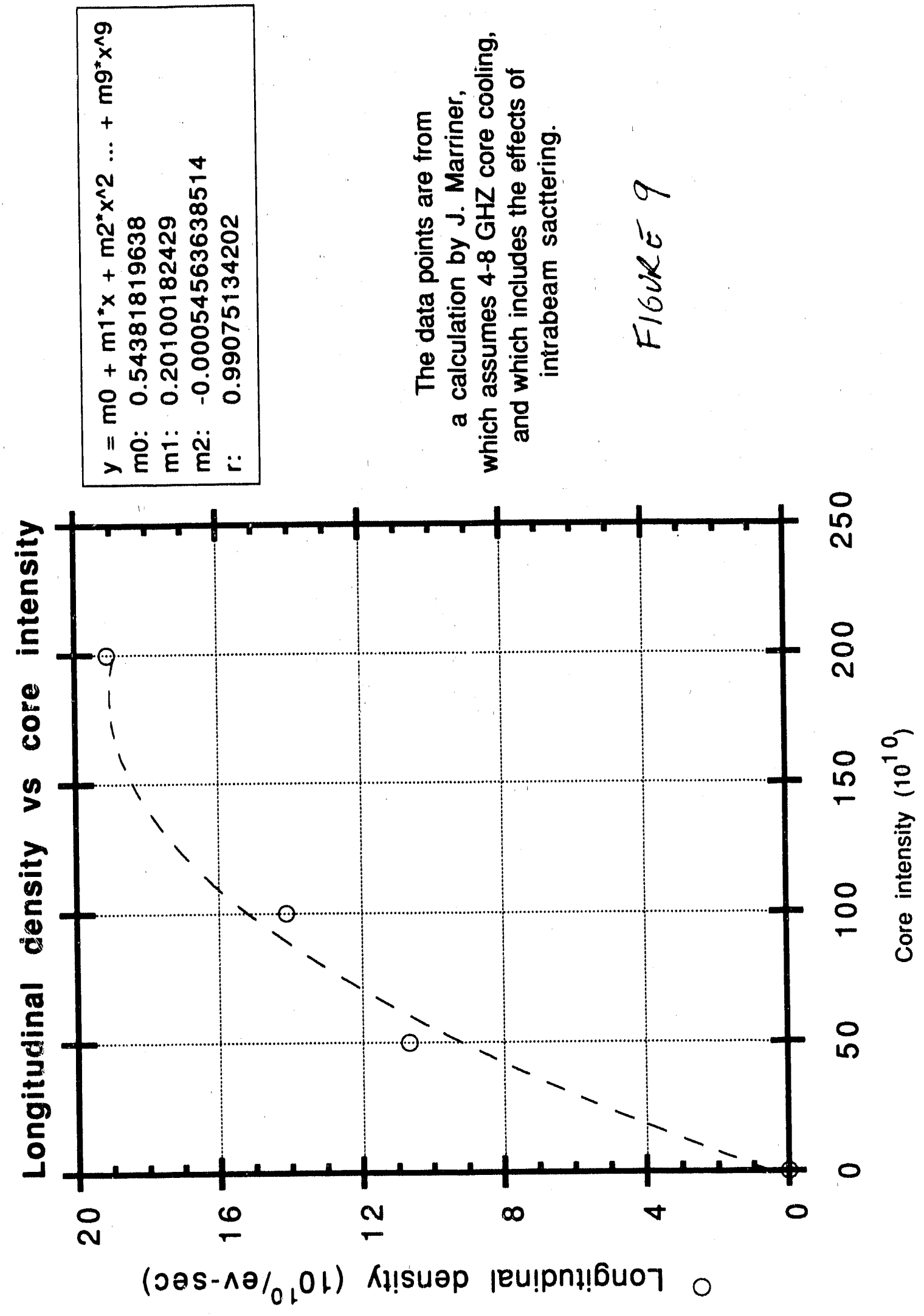
Table 2: List of parameters used for each of the curves shown in figs 4-8

\begin{tabular}{|l||l||l|l||l|l|l||}
\hline Figure & C & P & $\mathbf{Y}_{0}$ & E & $\begin{array}{l}\text { Stack-tail } \\
\text { B W }\end{array}$ & Disk file \\
\hline \hline & .384 & 1.7 & 7 & 3 & $1-2 \mathrm{GHz}$ & LIMITS.STACK1 \\
\hline 5 & .5 & 1.7 & 10 & 1.5 & $1-2 \mathrm{GHz}$ & LIMITS.STACK2 \\
\hline 6 & .5 & 3 & 14 & 1.5 & $1-2 \mathrm{GHz}$ & LIMITS.STACK3 \\
\hline 7 & .667 & 5 & 14 & 1.5 & $1-2 \mathrm{GHz}$ & LIMITS.STACK4 \\
\hline 8 & .667 & 5 & 14 & 1.5 & $2-4 \mathrm{GHz}$ & LIMITS.STACK5 \\
\hline
\end{tabular}

\subsection{Antiproton Source Unstacking Fraction}

The unstacking fraction, $\mathrm{f}$, is calculated as follows. The Accumulator core is assumed to contain a total amount of beam $\overline{\mathrm{N}}_{\mathrm{A}}^{\max }$, with a Gaussian distribution in longitudinal emittance $\mathrm{k}$ :

$$
d \bar{N}_{A} / d \kappa=\rho(\kappa)=\bar{N}_{A}^{\max } \exp \left(-\kappa^{2} / 2 \sigma_{K}{ }^{2}\right) / \sqrt{ }(2 \pi) \sigma_{K}
$$

The peak longitudinal density, $\rho(0)$, is given by

$$
\rho(0)=\bar{N}_{A}^{\max } / \sqrt{ }(2 \pi) \sigma_{K}=\rho_{0}
$$

In terms of this quantity, we can write

$$
\rho(\kappa)=\rho_{0} \exp \left(-\kappa^{2} \pi \rho_{0}^{2} / \bar{N}_{A}^{\max } 2\right)
$$

Unstacking proceeds as follows. For each of the B bunches, the unstacking process extracts a portion of the core (of longitudinal emittance $\kappa_{B}$ ) using an rf system, bunches this beam into roughly $1053 \mathrm{MHz}$ bunches (each of emittance $\kappa_{\mathrm{B}} / 10$ ), and injects it into the Main Ring for acceleration to 150 $\mathrm{GeV}$. Because the beam must go through transition in the Main Ring, the longitudinal emittance per $53 \mathrm{MHz}$ bunch cannot exceed roughly $0.1-0.15 \mathrm{eV}$ sec: this requires

$$
\begin{aligned}
& \kappa_{B} / 10<.1-.15 \text { ev-sec; } \\
& \kappa_{B}<1-1.5 \text { ev-sec. }
\end{aligned}
$$

After acceleration in the Main Ring to $150 \mathrm{GeV}$, these 10 bunches are coalesced to form one $53 \mathrm{MHz}$ bunch for injection into the Tevatron for collider operation. During the coalescing process, the total longitudinal 
emittance of the coalesced bunch grows to roughly 3-4 ev-sec, roughly independent of $\kappa_{\mathrm{B}}$.

If the collider is operated with $B$ bunches, then the total longitudinal emittance which must be removed from the Accumulator core is $\kappa_{B} B$. The amount of beam which corresponds to this emittance is

$$
\begin{aligned}
\bar{N}_{A}^{\text {unstack }} & =\int_{-\kappa_{B} / 2}^{\kappa_{B} / 2} \rho(\kappa) d \kappa \\
& =\bar{N}_{A}^{\max } \operatorname{erf}\left(\kappa_{B} B \sqrt{ } \pi \rho_{0} / 2 \bar{N}_{A}^{\max }\right)
\end{aligned}
$$

Thus, the unstacking fraction, $\mathrm{f}=\overline{\mathrm{N}}_{\mathrm{A}}^{\text {unstack }} / \overline{\mathrm{N}}_{\mathrm{A}}^{\text {max }}$, is

$$
f=g_{u} \operatorname{erf}\left(\kappa_{B} B \sqrt{ } \pi \rho_{0} / 2 \bar{N}_{A}^{\max }\right)
$$

where $g_{u}$ is an empirical de-rating factor which is inserted because the rf unstacking process is not completely efficient; typically $g_{u}=0.75$.

If $\sigma_{K}$ is independent of $\bar{N}_{A}^{\text {max }}$, then $p_{0}$ is linear in $\bar{N}_{A}^{\text {max }}$ and $f$ is independent of the stack size. In actual practice, the Accumulator core width $\sigma_{\kappa}$, which is determined by the equilibrium between the longitudinal core cooling systems and longitudinal heating mechanisms in the Accumulator, grows slowly with $\overline{\mathrm{N}}_{\mathrm{A}}$. The value of $\sigma_{\mathrm{K}}$ also depends on the bandwidth of the core cooling systems, and is reduced with a $4-8 \mathrm{GHz}$ system over that of the 2$4 \mathrm{GHz}$ system present for the 1988-89 collider run. Fig. 9 shows the expected dependence of the core density $\rho_{0}$ on $\overline{\mathrm{N}}_{\mathrm{A}}$ with the new $4-8 \mathrm{GHz}$ cooling system. Saturation of the density growth (increase in $\sigma_{K}$ with $\bar{N}_{A}$ ) is seen to occur at stacks in excess of $\bar{N}_{A}=100$. The dependence of the peak longitudinal density $\rho_{0}$ on the stack size $\bar{N}_{A}$ is parameterized in the model as a quadratic:

$$
\rho_{0}\left(\bar{N}_{A}\right)=\alpha_{1}+\beta_{1} \bar{N}_{A}+\eta \bar{N}_{A}^{2}
$$

The values of the constants in equation (27) are determined either from empirical data ${ }^{1}$ (for the $2-4 \mathrm{GHz}$ cooling system used in the 1988-89 run) or from the information shown in fig. 9 (for the new 4-8 GHz system).

\subsection{Antiproton Source Transverse Emittance.}

The dependence of the antiproton source transverse emittance $\bar{\varepsilon}_{\mathrm{A}}$ in the Accumulator on the stack size $\bar{N}_{A}$ results from the equilibrium between transverse stochastic cooling of the core, and transverse heating mechanisms 
such as intrabeam scattering. This dependence is determined empirically from data collected during the last collider run ${ }^{1}$; it is parameterized as a quadratic dependence, as given specifically in eq. 18. For the new $4-8 \mathrm{GHz}$ core cooling system, the empirical parameters have been scaled appropriate to an increase in the transverse density by a factor of two, which is expected theoretically and is consistent with the observations (in the absence of ion effects).

\subsection{Antiproton Transfer Efficiency}

As discussed above in section 3.3, the antiproton transfer efficiency $r$ is the product of three individual transfer efficiencies, as expressed in equation (7). The efficiency $r_{A}$ depends on the antiproton transverse emittance $\bar{\varepsilon}_{\mathrm{A}}$. The explicit dependence is expressed by the equation,

$$
r_{A}\left(\bar{\varepsilon}_{A}\right)=\alpha_{r}+\beta_{r} \bar{\varepsilon}_{A}+\gamma_{r} \bar{\varepsilon}_{A}^{2}
$$

The values of the constants in equation 28 have also been determined empircally ${ }^{1}$. Since $\bar{\varepsilon}_{A}$ depends on $\bar{N}_{A}$ through equation $18, \mathrm{r}_{A}$ also depends on $\bar{N}_{A}$. The efficiencies $r_{M}$ and $r_{T}$ are taken as constants in this model.

\subsection{Operational efficiency}

In order to account for the downtime which is inevitable in complex systems, we 'erine an "operational" average luminosity $\left\langle\mathrm{L}_{\mathrm{a}}\right\rangle$, and an "operational" antiproton source stacking rate $<R>$. These quantities are in general less than the quantities $\mathcal{L}_{a}$ and $R$, defined above in the model without operational considerations.

As a simp! a approximation to reality, we take the relations between the model's quantities and the operational quantities to be,

$$
\begin{aligned}
& \left\langle\mathcal{L}_{\mathrm{a}}>=\mathrm{g}_{1} \mathrm{~L}_{\mathrm{a}}\right. \\
& <\mathrm{R}>=\mathrm{g}_{\mathrm{s}} \mathrm{R}
\end{aligned}
$$

where $g_{l}$ and $g_{s}$ are fractions expressing the ratio of uptime to total scheduled time for the collider and antiproton source stacking systems respectively.

Although this sort of approach is appropriate for the antiproton source stacking system, in which downtime simply causes a net reduction in the average stacking rate, it is questionable whether it is correct for the collider. This is because a failure of the collider, in addition to introducing downtime for repair which diminishes the average luminosity, also has an impact due to the need to refill from the limited supply of antiprotons. 
Hence, the reduction in the average luminosity may not simply be the ratio of collider downtime to total scheduled time. In order to provide a somewhat better estimate, the following hypothesis is made:

Consider $M$ stores, with each store labelled by an index $j$, where $j$ runs from 1 to $\mathrm{M}$. A fraction $\eta$ of the $\mathrm{M}$ collider stores are not characterized by failure; these $\eta \mathrm{M}$ stores are terminated after the optimum store time $T$, as computed in the model described above. The storage time of each of these "good" stores is $\mathrm{T}_{\mathrm{j}}^{\text {store }}=\mathrm{T}$.

The remaining (1- $\eta) M=M_{\text {fail }}$ stores "fail": that is, they terminate after a time $\mathrm{T}^{\text {fail }}$, where $\mathrm{T}_{\mathrm{j}}$ fail, the failure time of the $\mathrm{jth}$ store, is chosen randomly from a probability distribution

$$
\mathrm{dP} / \mathrm{dT}_{\mathrm{j}} \text { fail } \propto \exp \left(-\mathrm{T}_{\mathrm{j}}^{\mathrm{fail}} / \overline{\mathrm{T}^{\mathrm{fail}}}\right)
$$

The storage time of the $j$ th "bad" store is $\mathrm{T}_{j}$ store $=\mathrm{T}_{j}^{\text {fail }}$. After each "bad" store fails, there is a period $T_{\text {down }}$ during which the collider is inoperative because of necessary repairs; stacking is also assumed to cease during this time.

Each of the $\mathrm{M}$ stores contributes an integrated luminosity,

$$
\mathcal{L}_{\mathrm{Ij}}=\mathcal{L}_{0 j} \tau\left(1-\exp \left(-\left(\mathrm{T}_{\mathrm{j}}^{\text {store }}+\mathrm{T}_{\mathrm{q}}\right) / \tau\right)\right.
$$

where $\mathfrak{L}_{0 j}$ depends on the stack size at the beginning of the store, and the stack accumulates during the store duration $\mathrm{T}_{j}$ store. After the store ends, stacking ceases and there is a period of time equal to either $T_{S}$ (for a "good" store) or $\mathrm{T}_{s}+\mathrm{T}_{\text {down }}$ (for a "bad" store) before the ne:' $t$ store starts. Stacking is off during this period.

The total amount of time associated with these $M$ stores is

$$
\mathrm{MT}_{\mathrm{avg}} \text { store }=\mathrm{M}\left(\mathrm{T}_{\mathrm{s}}+\mathrm{T}_{\mathrm{q}}\right)+\eta \mathrm{MT}+(1-\eta) \mathrm{M}\left(\overline{\mathrm{T}^{\text {fail }}}+\mathrm{T}_{\text {down }}\right)
$$

The "operational" average luminosity is then

$$
\left\langle\mathrm{L}_{\mathrm{a}}\right\rangle=\sum_{\mathrm{j}=1}^{\mathrm{M}} \mathrm{L}_{\mathrm{Ij}} / \mathrm{MT}_{\mathrm{avg}} \text { store }
$$

whereas the total fractional uptime is

$$
\mathrm{gl}_{1}=1-(1-\eta) \mathrm{T}_{\text {down }} / \mathrm{T}_{\mathrm{avg}} \text { store }
$$

It is clear that in this case the simple relation given in equation 29 does not hold. As is illustrated in the computer calculations exhibited in the appendix, typical values from the 1988-89 collider run $\left(T^{\text {fail }}=9.5 \mathrm{hr}, \mathrm{T}_{\text {down }}=6\right.$ 
hrs, and $\eta_{1}=0.45$ ) give $\left\langle\mathrm{L}_{\mathrm{a}}\right\rangle / \mathrm{L}_{\mathrm{a}}=0.67$ and $\mathrm{gl}_{1}=0.84$ from equations 35 and 36 , respectively. For all of the calculations to be discussed below, we have used equation 29 , but we have taken $g 1=0.6$.

\section{Collider performance in the Upgrade}

\subsection{Computer programs}

The above model has been implemented in two computer programs written in VAX FORTRAN. One program, called LIMITS, essentially performs the calculations discussed in section 3.4, and produces the curves shown in figs. 4-8 as numerical output. This output is stored in the disk files shown in Table 2. This information, together with the other parameters of the model discussed above, is input to the second program, called LUMIN. This program performs the optimization discussed in sectic.. 3.2, thereby determining the optimum average luminosity, stacking and storage time, and optimum maximum stack.

The optimization is performed for each of three values of the parameter $\kappa_{B}$. This is done because the actual choice of the value of $\kappa_{B}$ is subject to the "soft" constraint indicated by equation 24 . This constraint is related to longitudinal effects in the Main Ring, which are not included in the model. The results of the optimization are presented under the heading, "STACK FOR THE OPTIMUM TIME". For the central value of $\kappa_{B}$, the program also computes the loy derivative of the average luminosity with respect to each of the model parameters, in order to estimate the sensitivity of the average luminosity to each of the model parameters.

The average luminosity and stacking rate computed by the model are the "operational" quantities as defined by equations 29 and 30 . However, the program also uses a Monte Carlo simulation technique to go through the calculations expressed by equations 35 and 36, for comparison. This part of the output is labelled, "sim results".

As the last step, the program repeats the calculations of the optimized quantities using the simplified approach discussed in the latter part of section 3.2. This is labelled as "STACK TO NSMAX" in the program's output. Log derivatives of the average luminosity are also calculated in this case.

The format and meaning of the input and output parameters for the two programs is fully documented through comments imbedded in the FORTRAN.

\subsection{Results}

As an example, the programs have been run for several sets of parameters, corresponding to the current definitions of the various phases of the Fermilab III upgrade, from the 1988-89 collider run through operation with the Main Injector. The values used for the luminosity lifetime. 
correspond to calculated values at the beginning of each store; the calculations include the effects of intrabeam scattering, residual gas attenuation, and attenuation due to interactions at the beam collision points. Table 3 summarizes the results.

The actual output from the computer program LUMIN is given in the appendix to this report. In this output, the values for all the parameters described in Table 1 are given, for each step in the upgrade, together with the results of the model calculations which are summarized in Table 3.

\section{References}

1. G. Dugan, V. Bharadwaj, An Empirical Model for the Luminosity of the Fermilab Tevatron Collider, in Proceedings of the 15th International Conference on High Energy Accelerators, Toyko, 1990

2. J. Marriner, Pbar Note 511 


\begin{tabular}{|c|c|c|c|c|c|}
\hline \multicolumn{6}{|c|}{$\begin{array}{c}\text { Table 3: } \\
\begin{array}{c}\text { Collider Performance Parameters } \\
\text { in the Fermilab Upgrade }\end{array} \\
\end{array}$} \\
\hline & $\begin{array}{l}1988-89 \\
\text { Rum }\end{array}$ & \begin{tabular}{|l|}
$1991-2$ \\
Rum \\
\end{tabular} & 1993 Run & $\begin{array}{l}\text { 1994-5 } \\
\text { Rum }\end{array}$ & 1996 Run \\
\hline \multicolumn{6}{|l|}{ Parameter } \\
\hline CM energy $(\mathrm{GeV})$ & 1800 & 1800 & 1800 & 2000 & 2000 \\
\hline Number of bunches(maximum) & 6 & 6 & 6 & 36 & 36 \\
\hline Protons $/$ bunch $\left(10^{10}\right)$ at low- $\beta$ & 7 & 7 & 10 & 10 & 33 \\
\hline $\begin{array}{l}\text { Antiprotons } / \text { bunch } \\
\left(10^{10}\right) \text { at low }-\beta\end{array}$ & 3.1 & 6.1 & 6.9 & 1.8 & 3.5 \\
\hline $\begin{array}{l}\text { Total antiprotons extracted from } \\
\text { the core }\left(10^{10}\right)\end{array}$ & 28 & 50 & 60 & 102 & 145 \\
\hline $\begin{array}{l}\text { Antiproton longitudinal } \\
\text { emittance per bunch, extracted } \\
\text { from the core (eV-sec) }\end{array}$ & 1 & 1.25 & 1.25 & .5 & .5 \\
\hline $\begin{array}{l}\text { Antiproton transmission } \\
\text { efficiency }(\%)\end{array}$ & 65 & 74 & 70 & 63 & 87 \\
\hline $\begin{array}{l}\text { Invariant transverse emittance } \\
\text { (95\%, } \pi \text { mm-mrad) at low- } \beta \text { : } \\
\text { proton (antiproton) }\end{array}$ & $25(18)$ & $15(13)$ & $15(15)$ & $15(20)$ & $30(22)$ \\
\hline $\begin{array}{l}\text { Longitudinal emittance }(95 \% \text {, } \\
\text { eV-sec) at low- } \beta \text { : proton } \\
\text { (antiproton) }\end{array}$ & $3(3)$ & $3(3)$ & $3(3)$ & $3(3)$ & $3(3)$ \\
\hline$\beta^{*}(\mathrm{~m})$ & .55 & .5 & .5 & .5 & .5 \\
\hline $\begin{array}{l}\text { Antiproton stacking rate } \\
\left(10^{10} / \text { hour }\right)\end{array}$ & 1.8 & 3.2 & 5.4 & 7.6 & 16.8 \\
\hline Initial luminosity lifetime (hr) & 35 & 17 & 15 & 22 & $\overline{16}$ \\
\hline $\begin{array}{l}\text { Average stack before } \\
\text { transfer }\left(10^{10}\right)\end{array}$ & 77 & 75 & 93 & 137 & 200 \\
\hline Optimum stacking time (hr) & 25 & 20 & 14 & 18 & 12 \\
\hline $\begin{array}{l}\text { Linear beam-beam tune } \\
\text { shift(Antiprotons) }\end{array}$ & .025 & .007 & .010 & .010 & .016 \\
\hline $\begin{array}{l}\text { Mean number of inelastic } \\
\text { interactions per crossing }\end{array}$ & .3 & 1 & 1.5 & .4 & 1.7 \\
\hline $\begin{array}{l}\text { INITIAL LUMINOSITY } \\
\left(10^{30} / \mathrm{cm}^{2} / \mathrm{sec}\right)\end{array}$ & 1.7 & 5.7 & 8.8 & 13.1 & 57.1 \\
\hline $\begin{array}{l}\text { AVERAGE LUMINOSITY } \\
\text { ( } \mathrm{pb}^{-1} \text { /week, assuming } 60 \% \\
\text { uptime) }\end{array}$ & 0.41 & 1.1 & 1.8 & 2.9 & 12.2 \\
\hline $\begin{array}{l}\text { INTEGRATED LUMINOSITY } \\
\text { per year }\left(\mathrm{pb}^{-1}\right)\end{array}$ & 21 & 57 & 94 & 151 & 630 \\
\hline
\end{tabular}


Appendix: Output from the program LUMIN for each step in the upgrade 


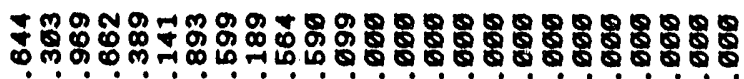

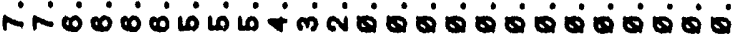

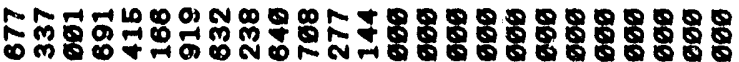

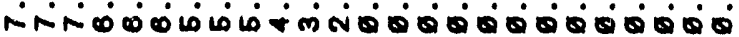

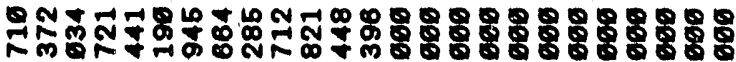

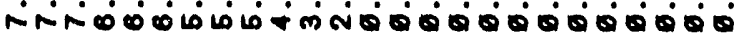

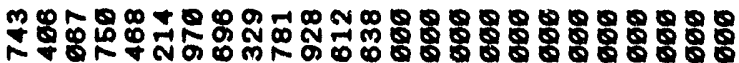

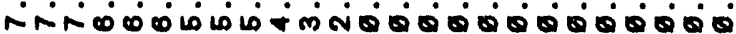

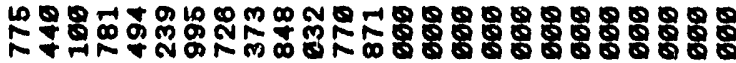

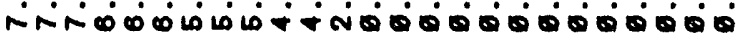

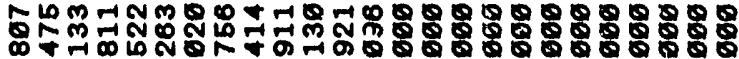

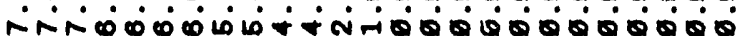

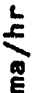

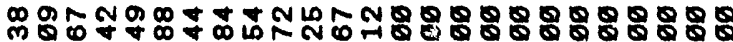

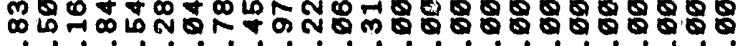

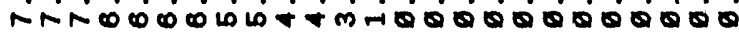

$\stackrel{\infty}{\infty}$

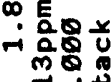

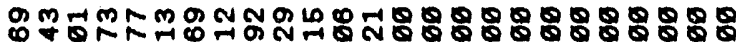
○ 最!

象昂

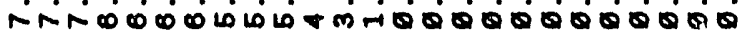

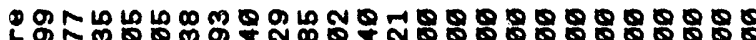
○

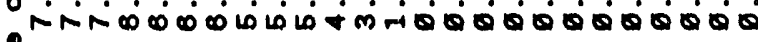

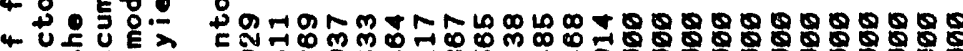
4

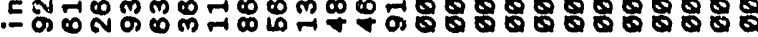

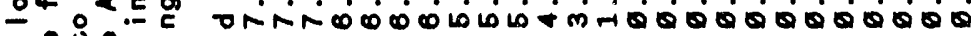
蛋兽

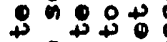

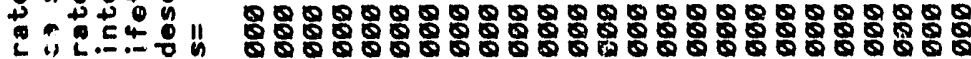

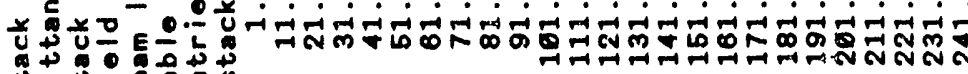

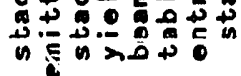



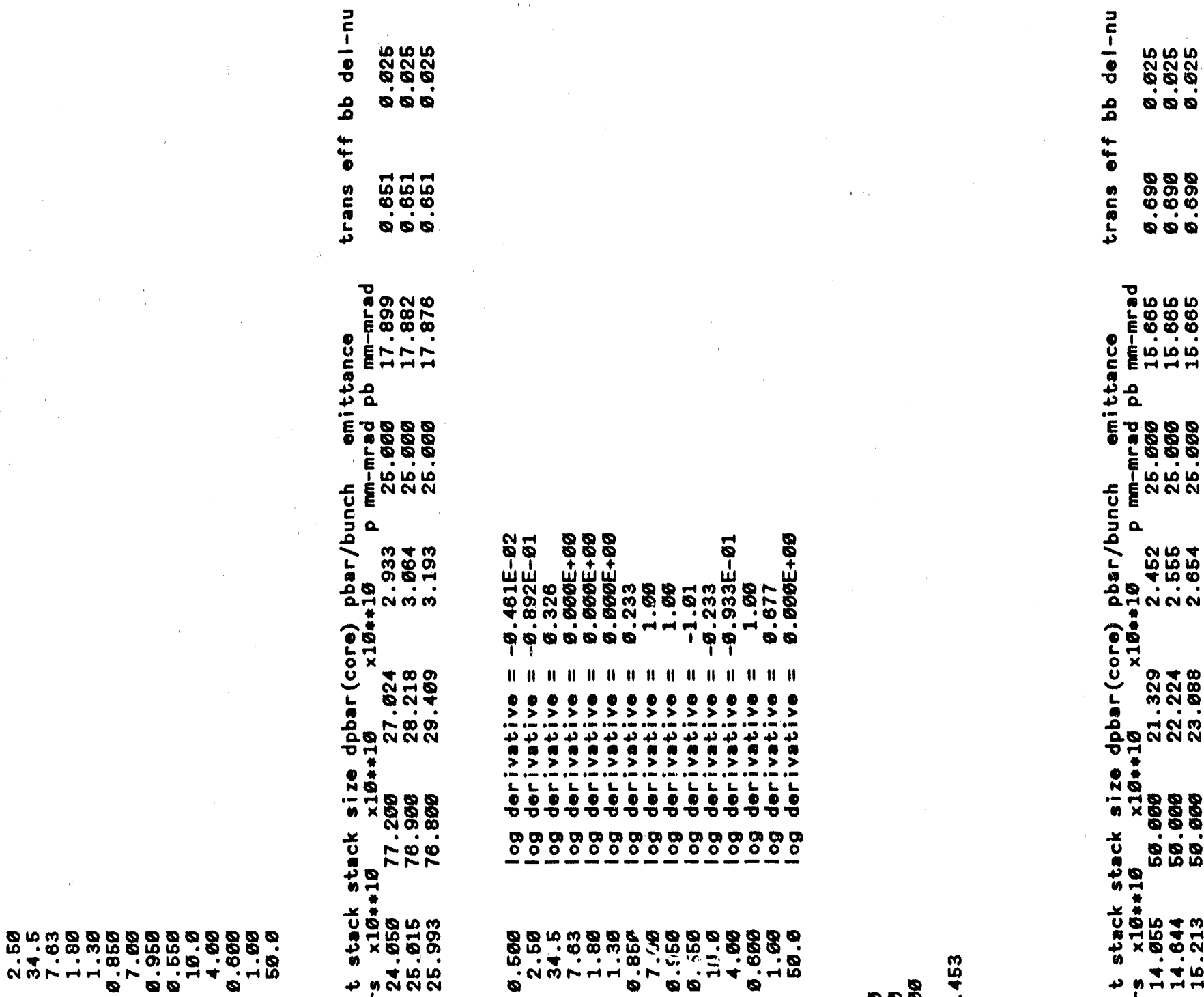

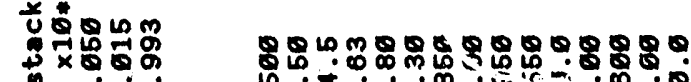

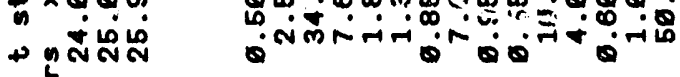
| | | | | | | | | | | | | | |
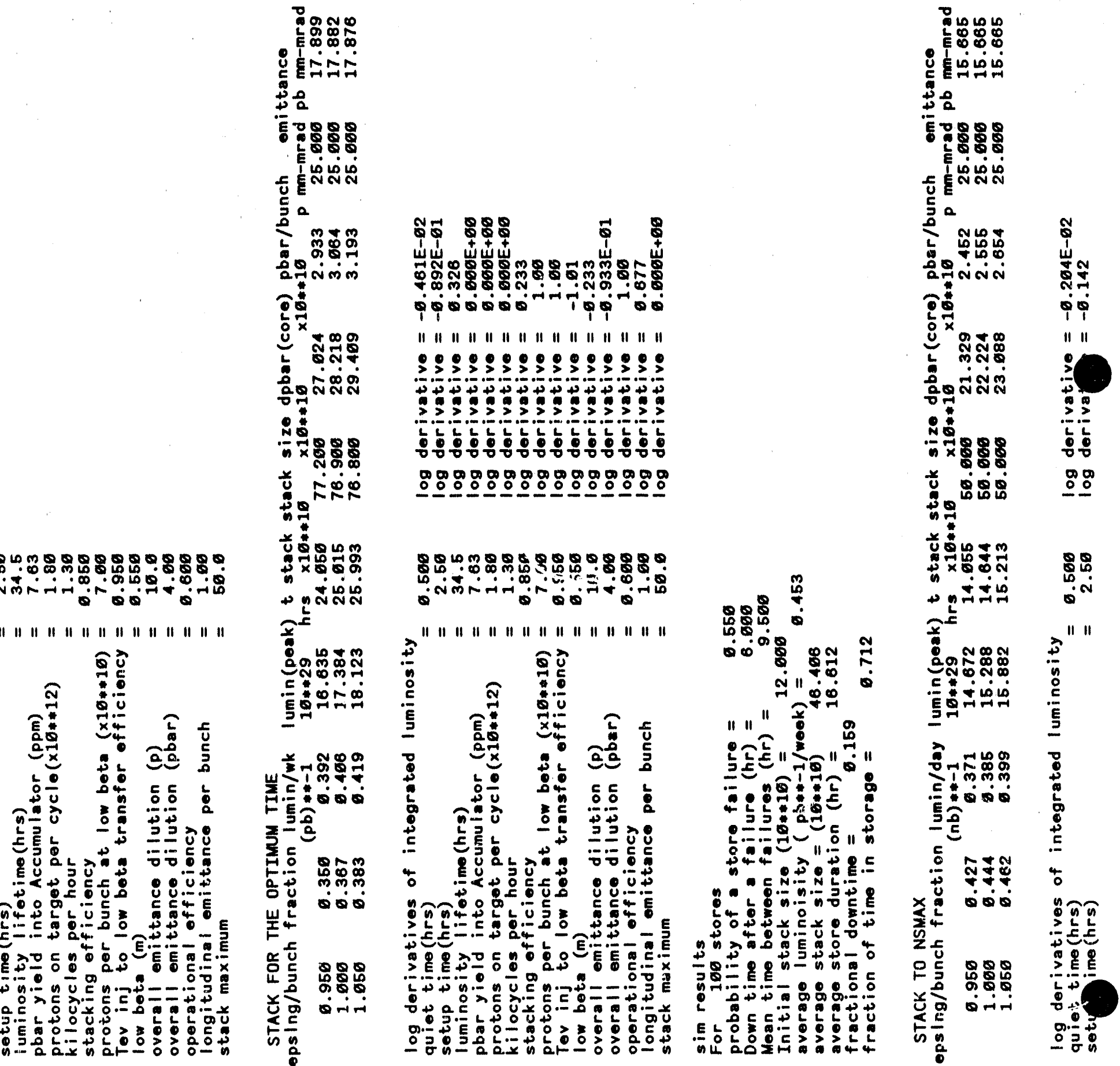


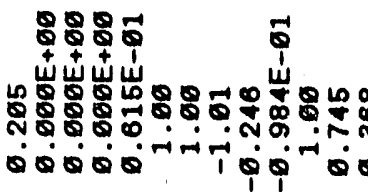

|| || || || || || || || || | | | |

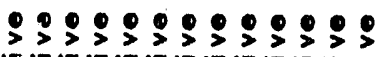

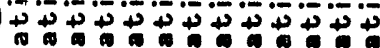

$\geq \geq \geq \geq \geq \geq \geq \geq \geq \geq \geq \geq \geq$

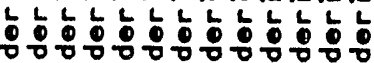

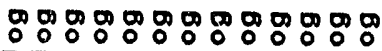

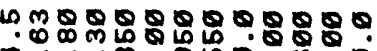

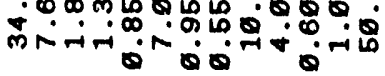

| | | | | | | | | | | | |

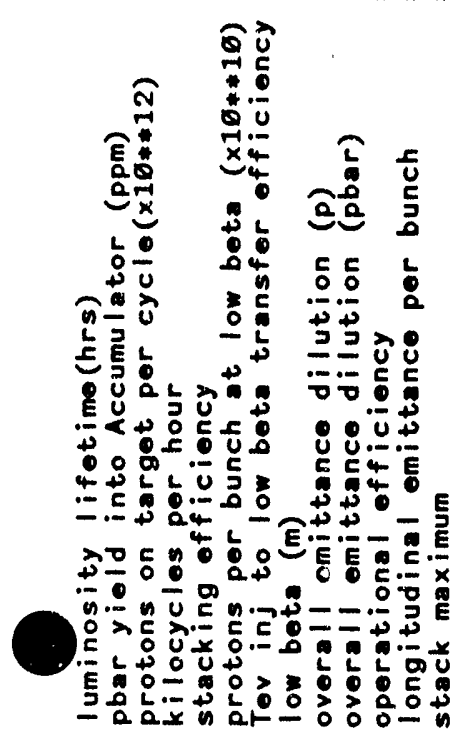




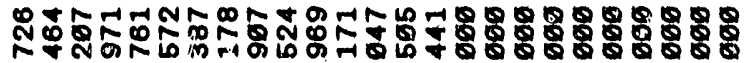

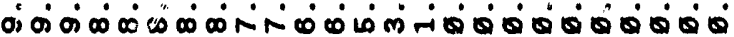

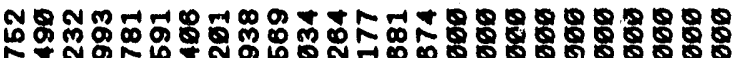

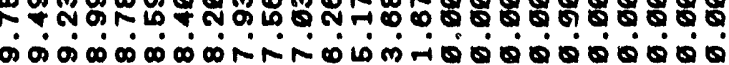

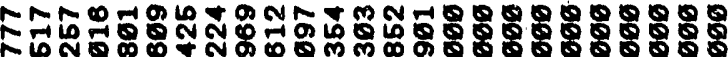

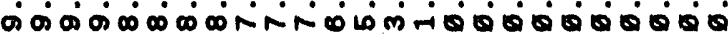

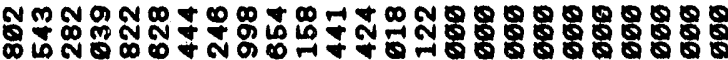

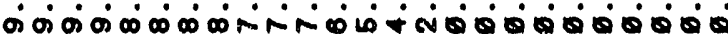

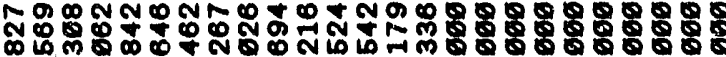

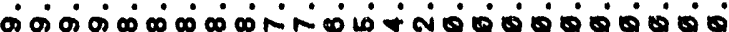

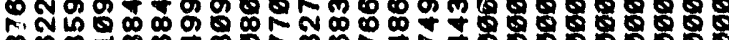
\%

ํำ

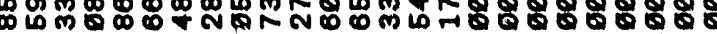

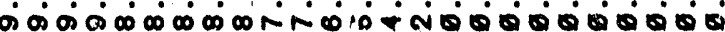

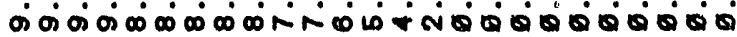

及

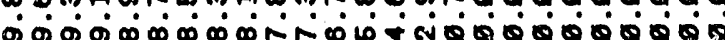
-8: $\operatorname{lin}^{2}$ orit 114

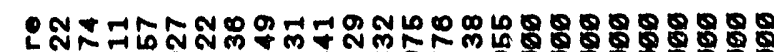
○N

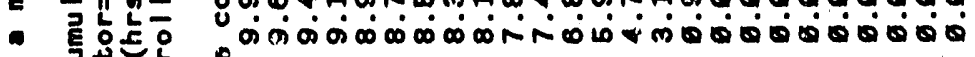
E

更 $\stackrel{\circ}{\ddagger}$

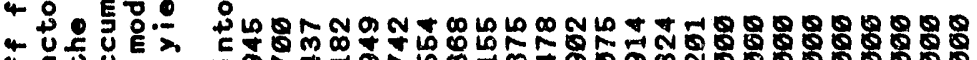
年 -

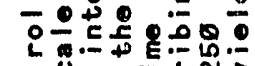

c 980 in

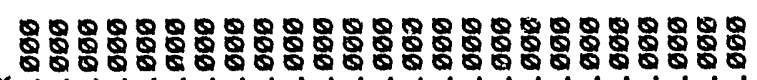
U⿱艹 

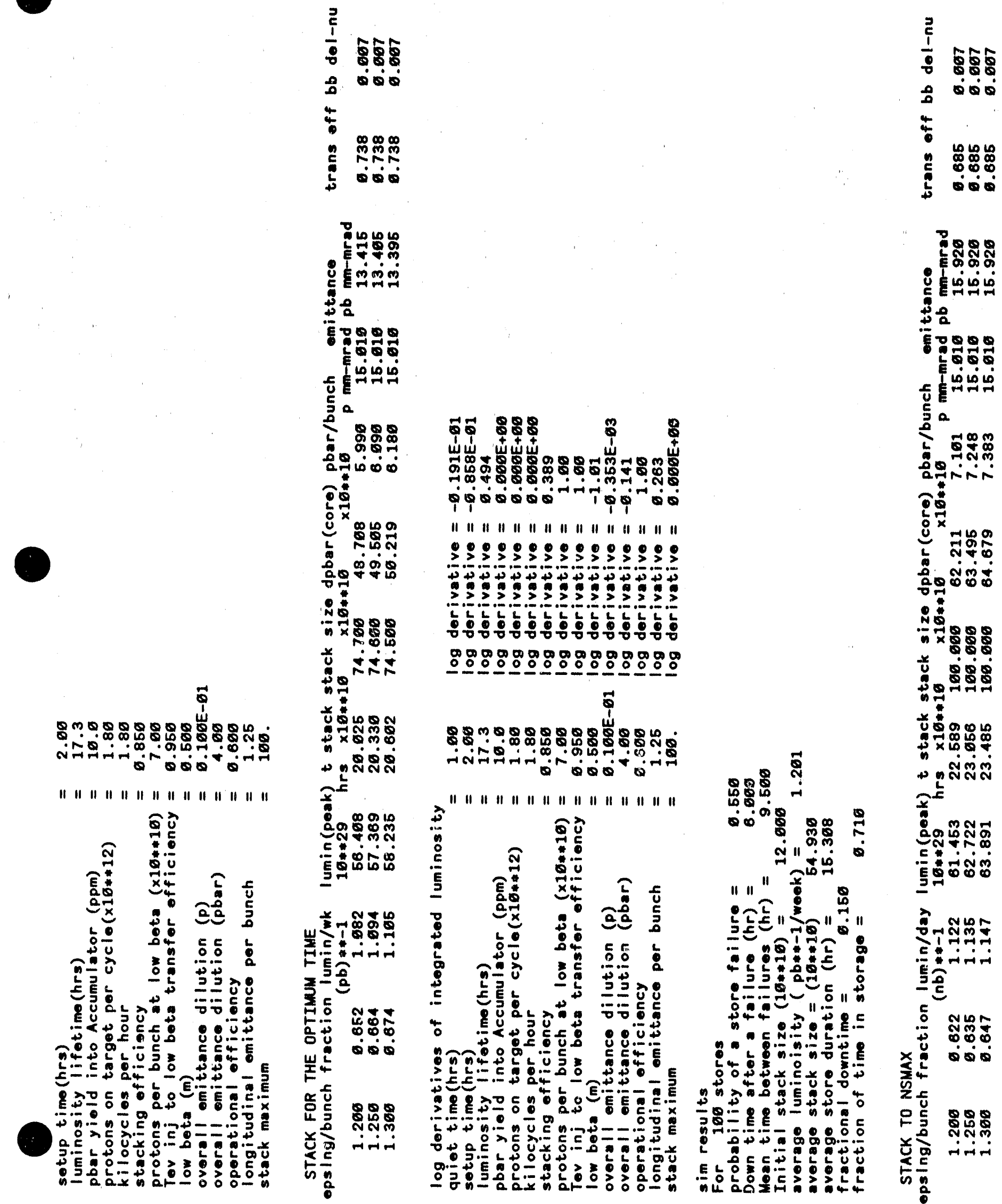

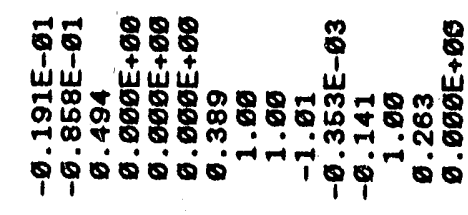

|| || || || || || || || || | | | | | | |

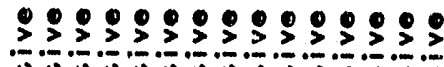

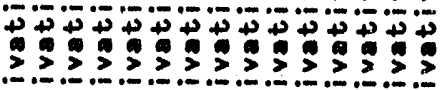

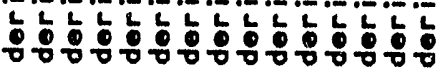

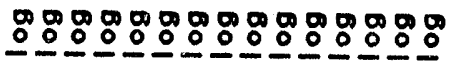

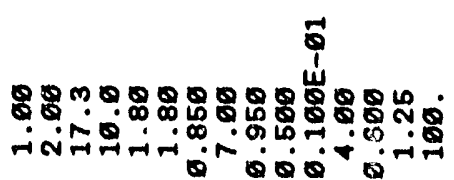

| || || || | | | || || | | | | |

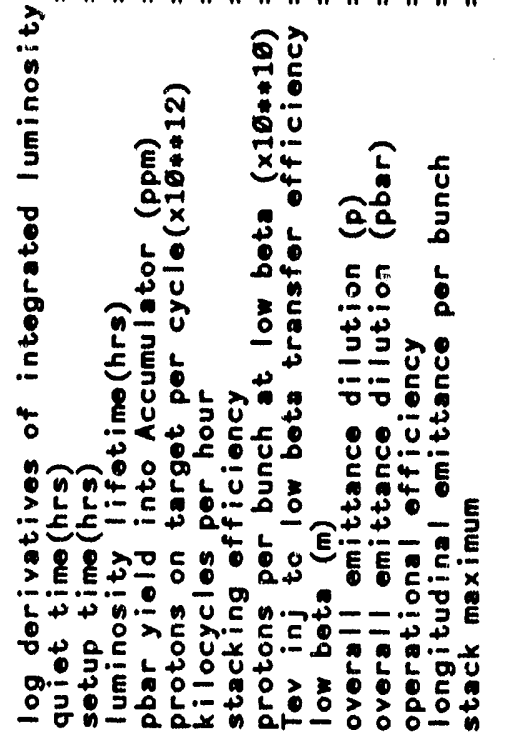

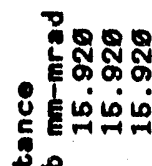
$\$$

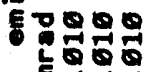

ธำ

定a

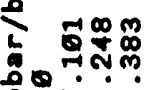

ㅇำiำ

o

家

ำำ

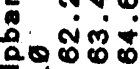

:

我㩆

48

‥

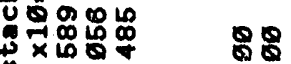

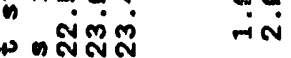

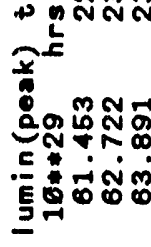

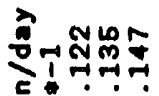

हैं⿰彳

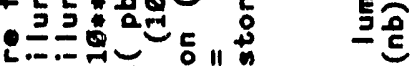

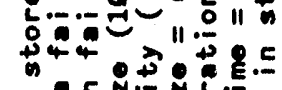

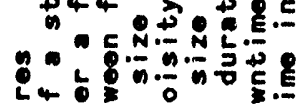

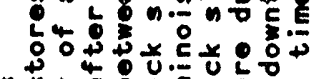

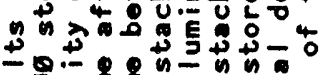

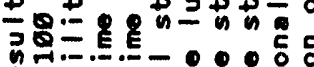

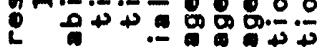

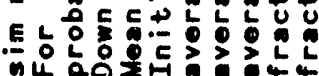

焉

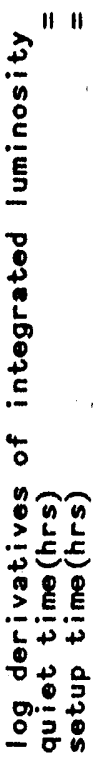



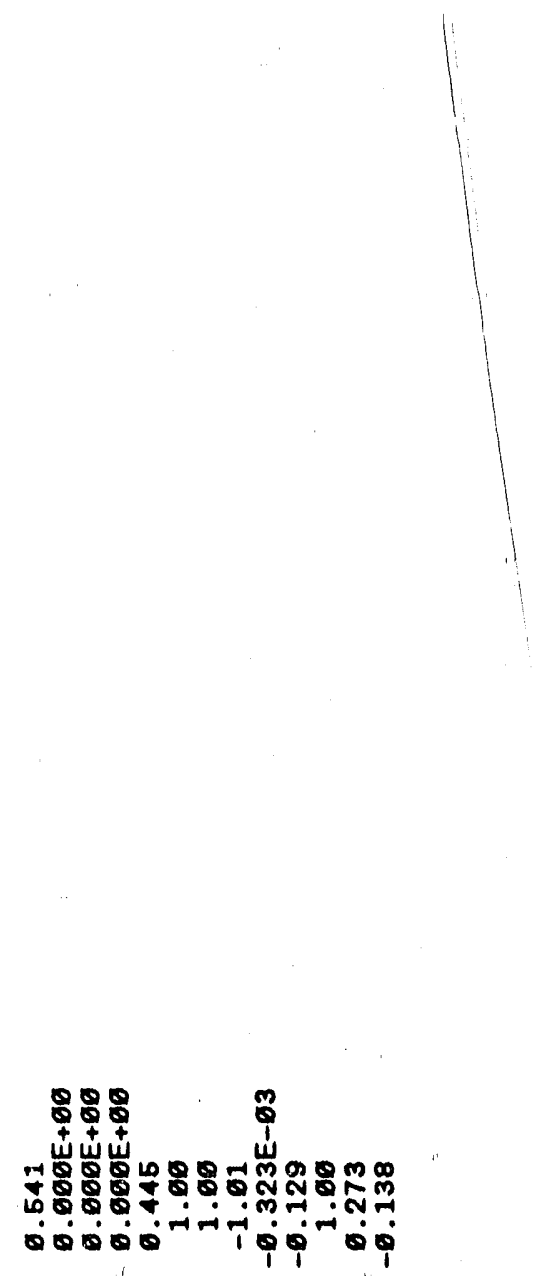

"1. | | | || || || | | | | | |

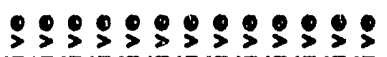

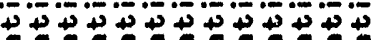
$>>>>>>>>>>>>>$

ว

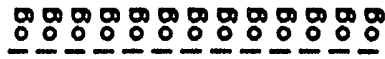

m๑989 | || || || || || || || | || ||

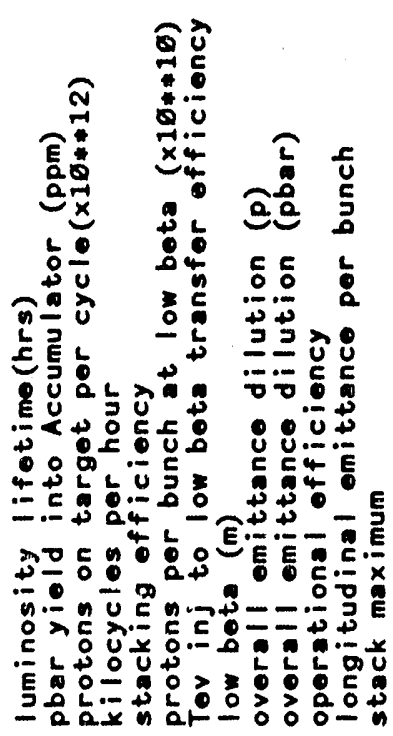




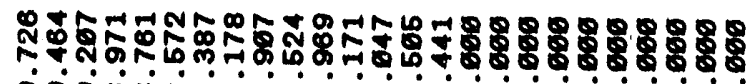
क

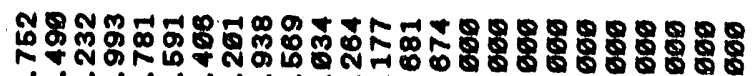

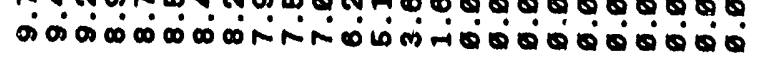

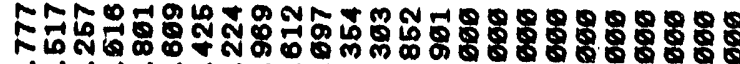

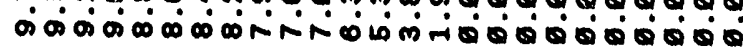

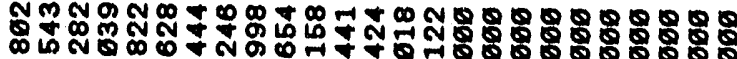

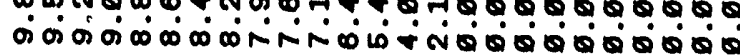

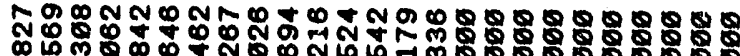

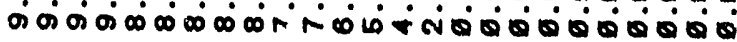

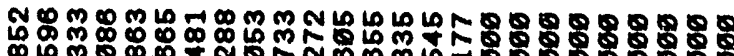

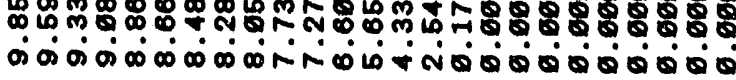

$\stackrel{2}{\frac{2}{5}}$

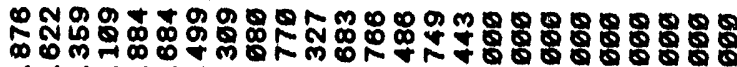

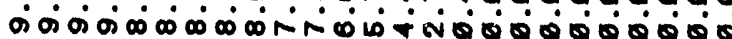

兽是

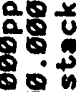

8.8

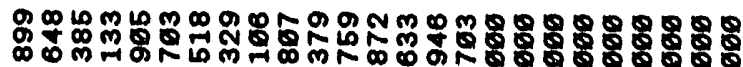

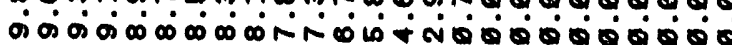
-

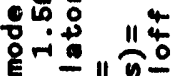

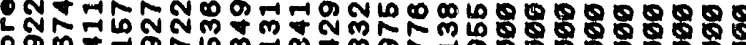

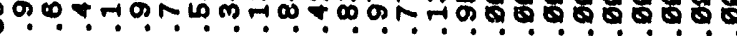
$\frac{8}{4}$

มั $4+0$

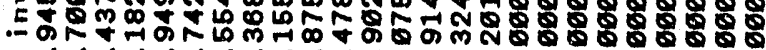

客 

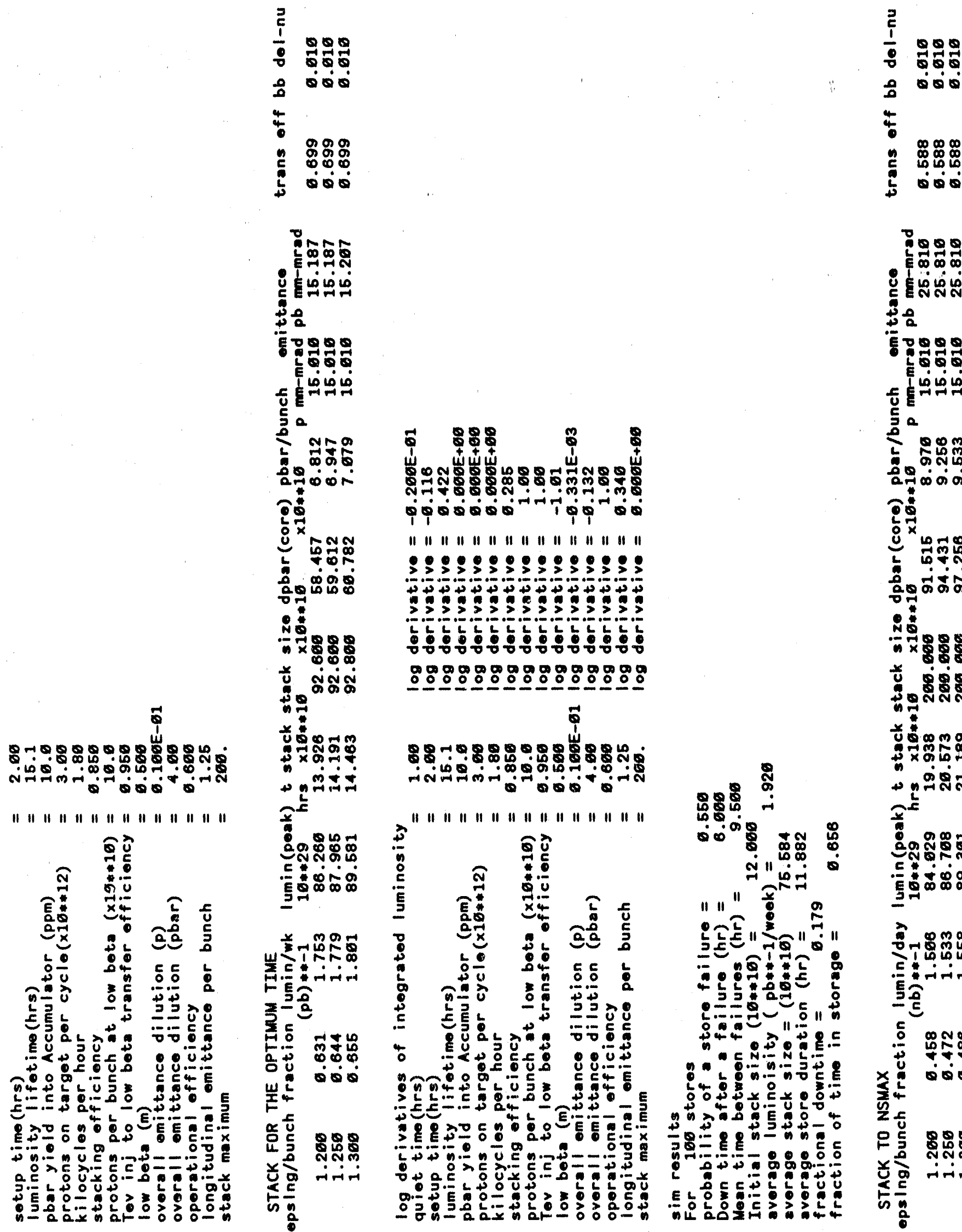

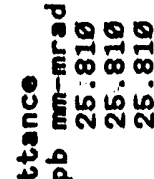

ธํำำำำ

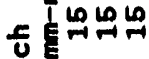

政

苛 a

西

ลำ

วิ

.

㻤

b

ลัषั๊์

.

웅

的我最昌

पे

पूलतล

की

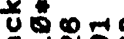

$5 \times 0$

मn mit

도․

قㅜํำ

E्ञ

美鮕曷

F

₹年

密

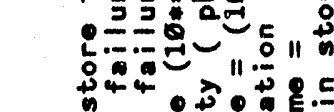

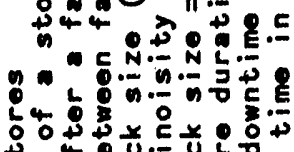

के

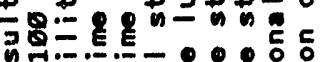

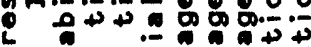

EL

政

บै.

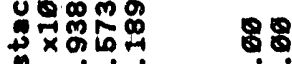

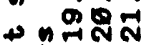

-in

政

خ"

우ำํํำ

E.

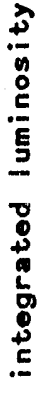

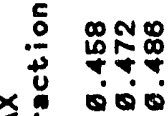

空

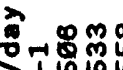

مَ

互定

4

量

옹

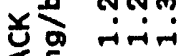

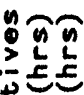

क \&

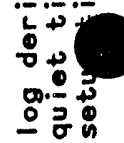




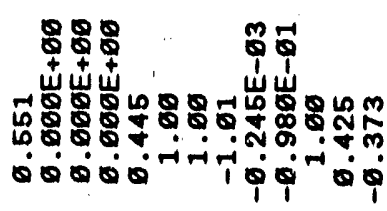
| || || || || || || || || || || || ||

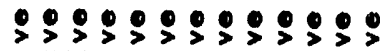
$4=$

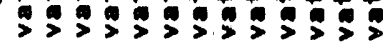

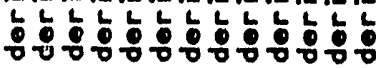

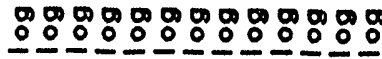

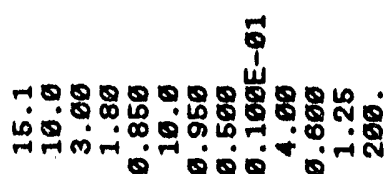
| | | | | | | | | | | | |

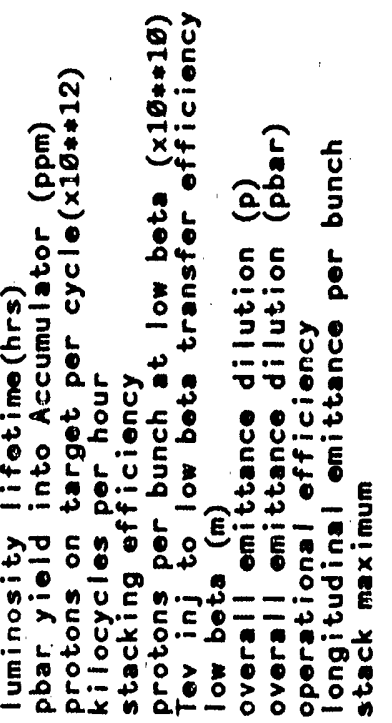




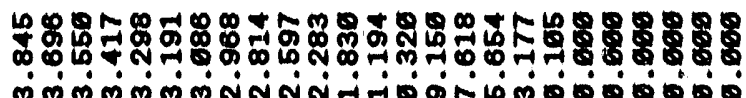

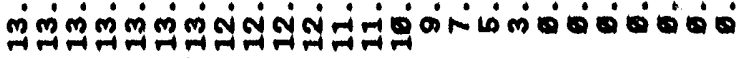

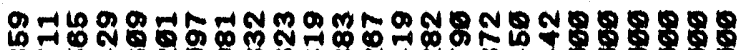
的范

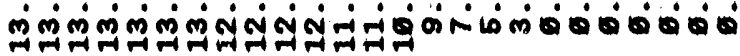

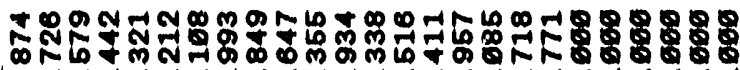
mingmpm

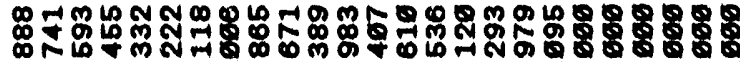

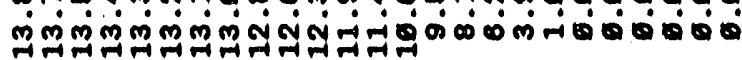

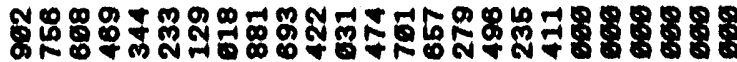

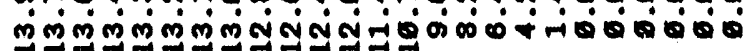

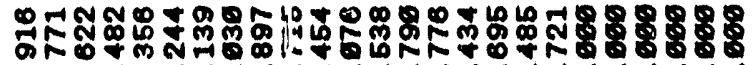
minmmingm

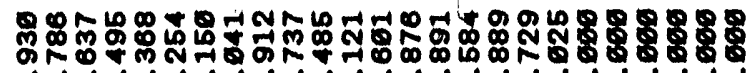
minmmm

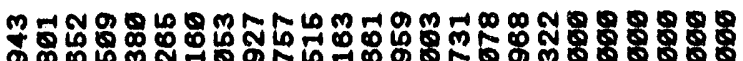

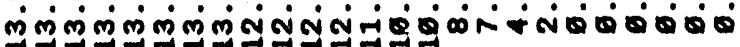

兽

ํ.ดำ

8.9

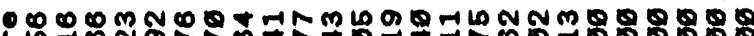
เด็๊

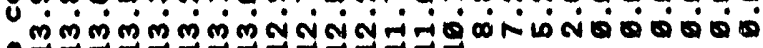
ț 
7
$\frac{1}{8}$
8
4
4
8

审

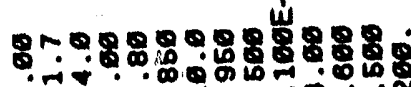

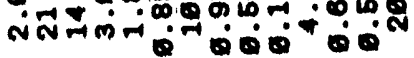

| | | | | | | | | | | | | |

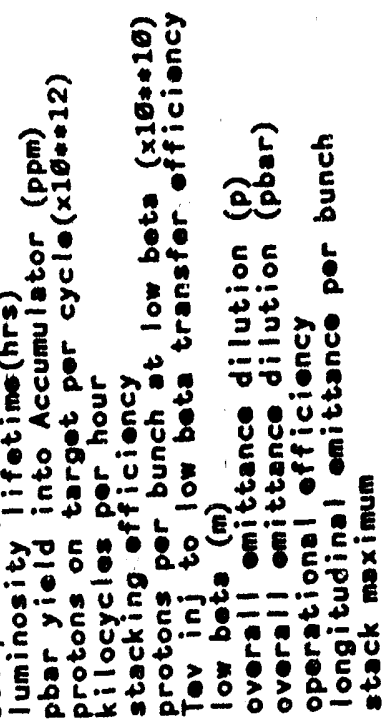

\section{ำำ \\ ह}

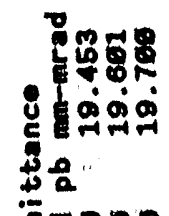

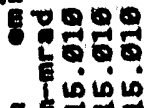

ธิ

5 a

20

兑

与.

웅웍웜

들

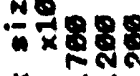

通觜

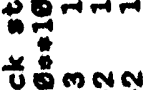

บำำ

कित्म

ว

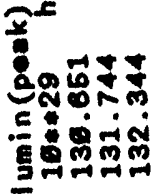

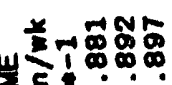

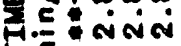

틍요

究

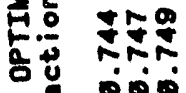

岸祀

铝吉

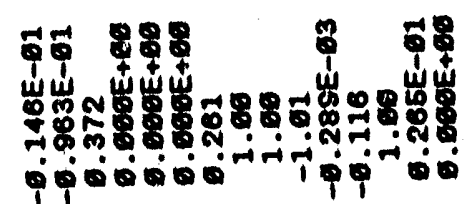

| || || || || || | | | | | | | | |

$\$ 9: 99: 999: 99:$

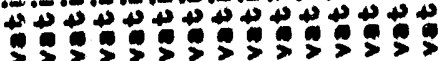

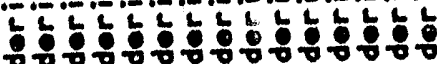

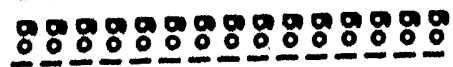

章
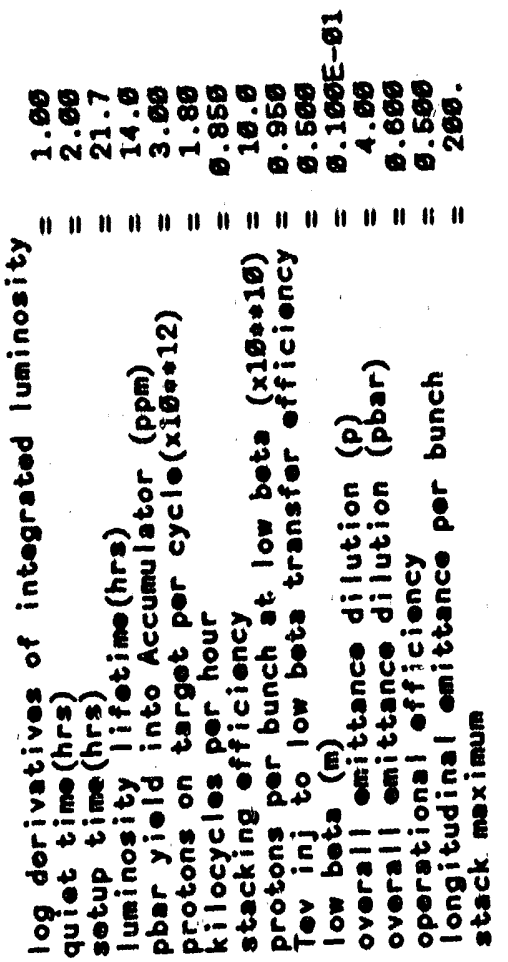

3
$\frac{1}{8}$
8
8
8

$\frac{9}{6} \frac{9}{6}$

000

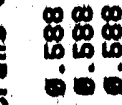

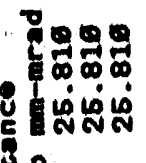
3

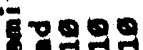

ตุอุด

f

รั

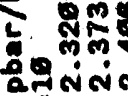

28

क्षेत

รับำ

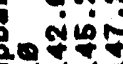

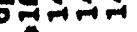

8

$\div \times \frac{1}{4} 8$

4

मूलक

․․․

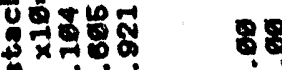

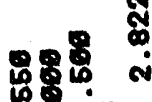

กสมส

1111

由.ंक

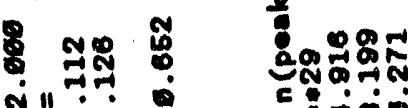

整要

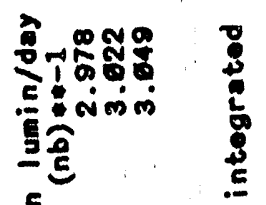

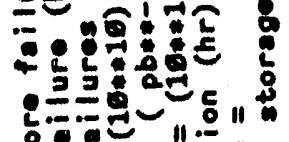
然

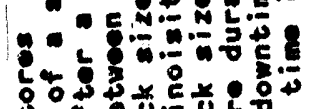

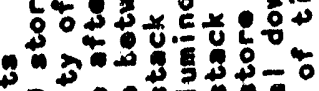
\$

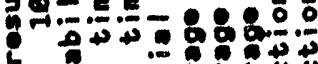

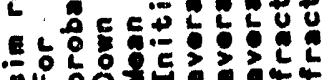

in

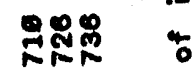

$\times 400$ $\div$

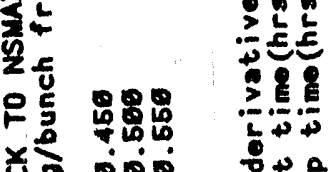

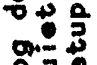
뭉요 


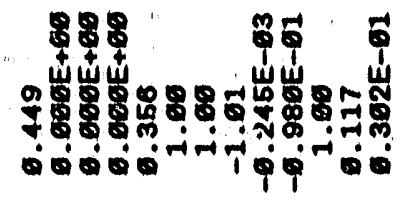
|| || || || || || || || || || || || ||
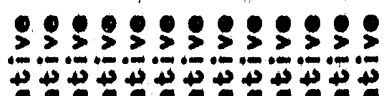

$>3>393>29>3>3$

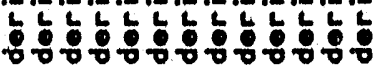

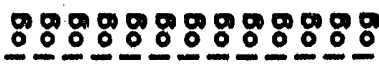

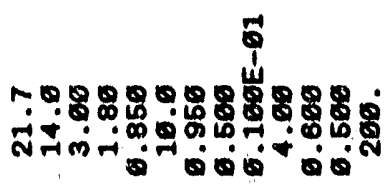

| | | | | | | | | | | | | |

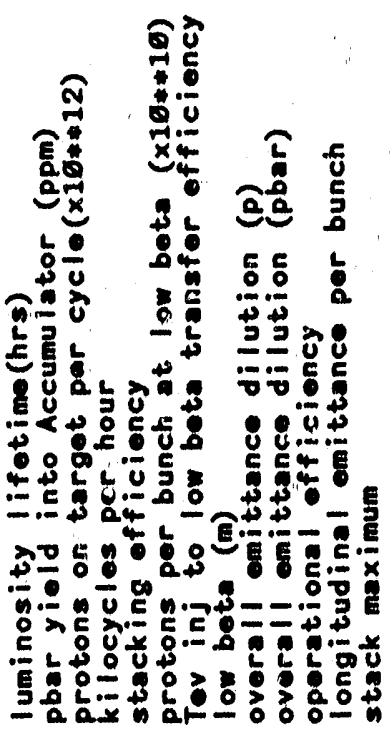




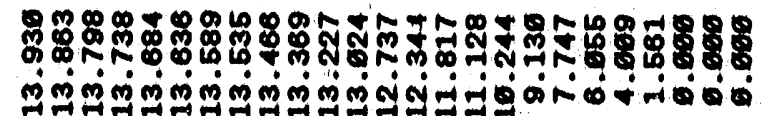

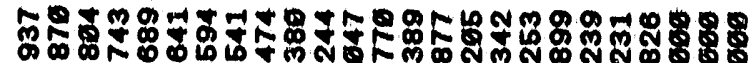

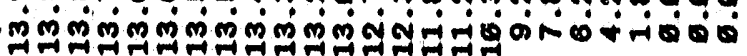

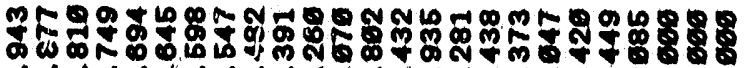

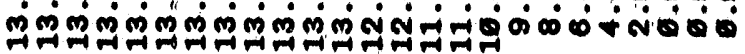

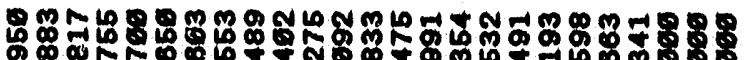

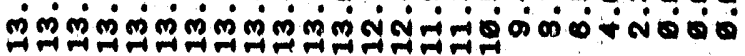

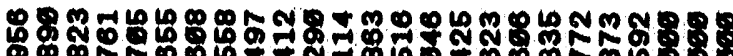
miñ

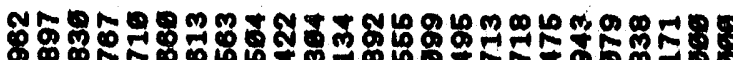

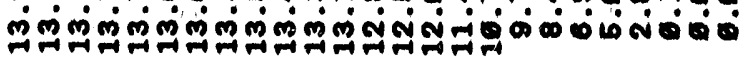

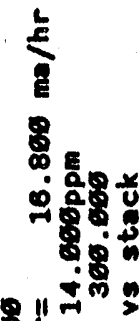

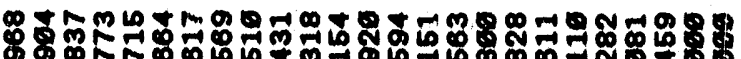

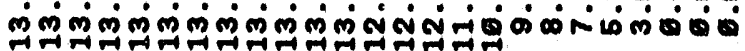

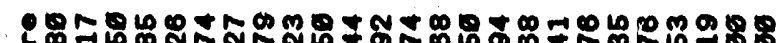

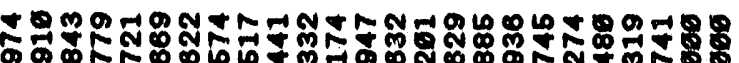

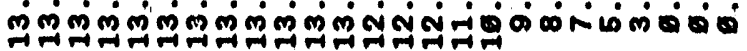

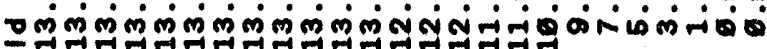
$2 \div \frac{0}{0}+\frac{0}{2}$ 


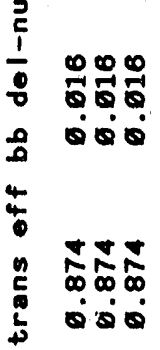

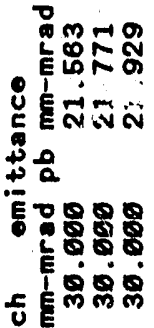

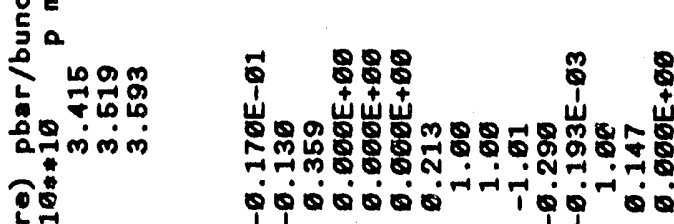

웅

$\overbrace{}^{\circ} \times$

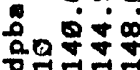

0

$\div \times 898$

n.

पै

草 จำใด Nल

| | | | | | | | | | | | | | | |

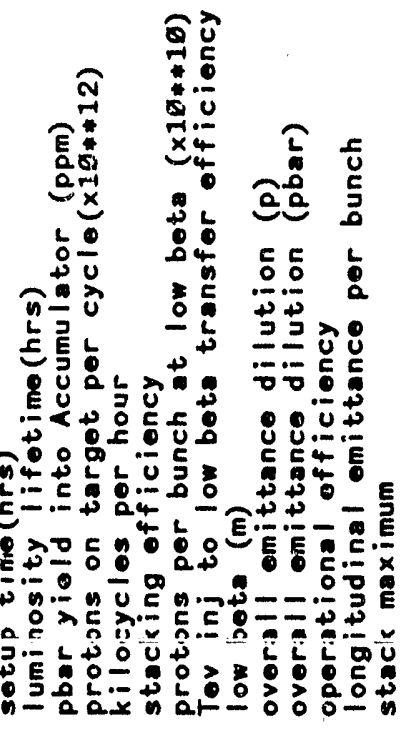

| || || || || || || || || || || || || || |

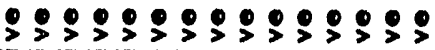

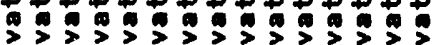

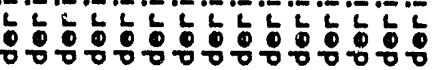

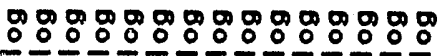

म

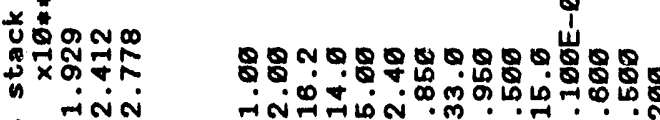

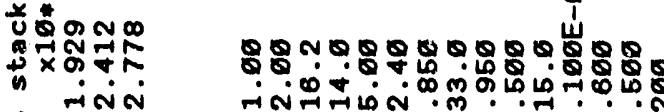

म न

| | | | | | | || || || | | | | | |

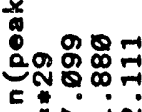

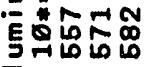

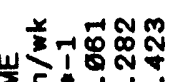

*ก่

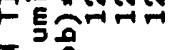

즈응

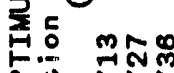

a $\operatorname{Rin}$

की०

唋岳 8
就市

बंबं

\section{ำดำ \\ Eัญ జ్ఞ

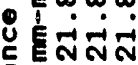

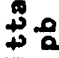

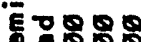

E.

屯ิ

อ

的

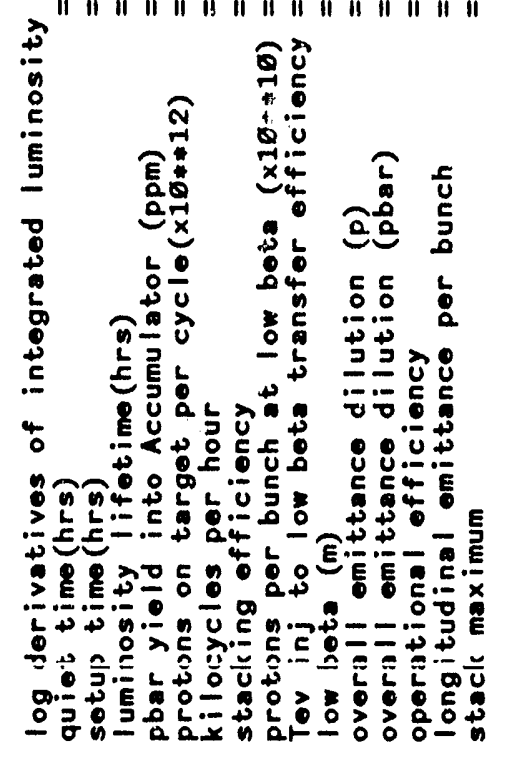

웅영

จं

ㄱำ 110

" " "

年

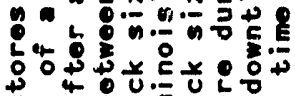

के

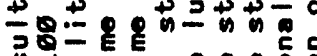

प̆न

E go

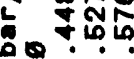

a.

20

to

บ

คิำ

ํㅡㄹ

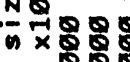

บ $8 \dot{8}$

บดกสล

둔

บับNL

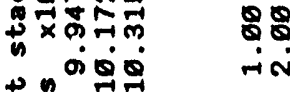

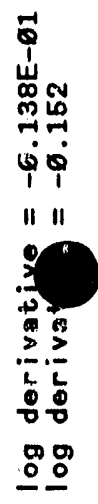

两

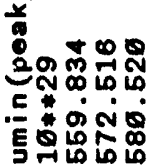

点"

จึ-

토ำ

틀오

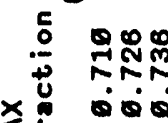

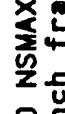

은

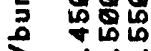

$\dot{=}=$ 



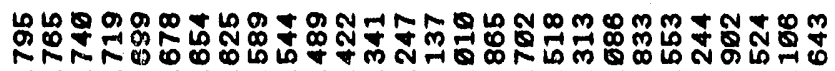

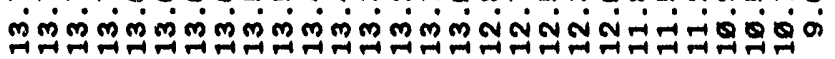

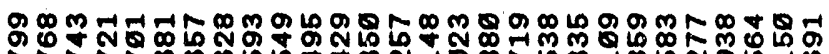

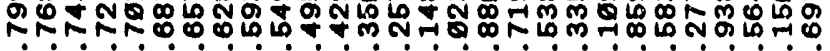

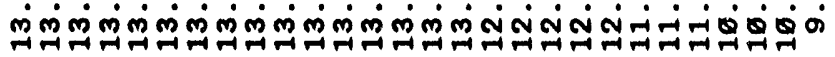

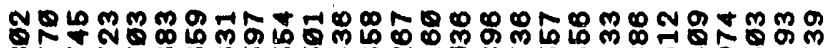

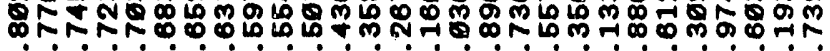

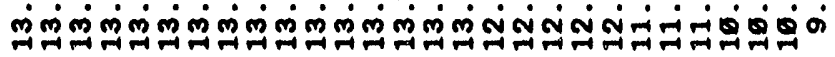

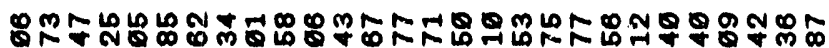
Ф下 순.

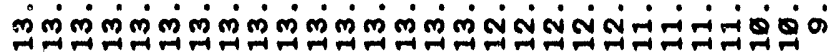

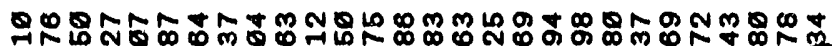

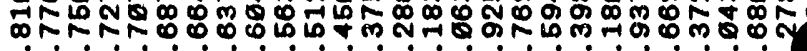

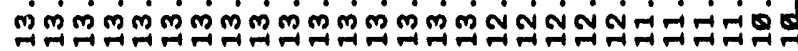

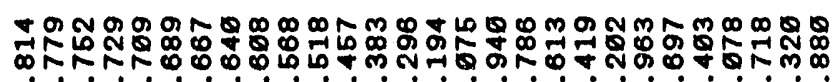

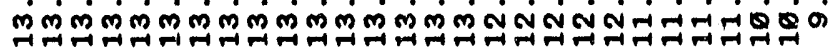

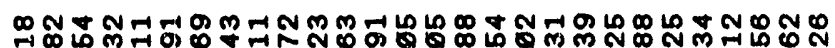

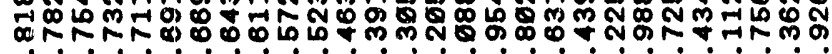

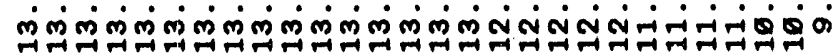

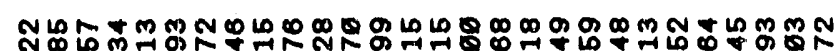
以

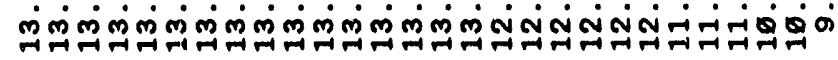

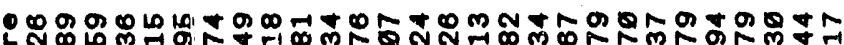
๑ N 0 $\frac{10}{2}$

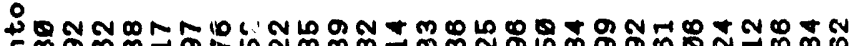
E ⿷匚⿳丨人丨 0 mingm

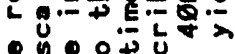


Q

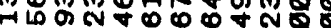

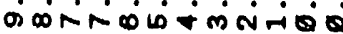

Nㅗㅇㅁำ

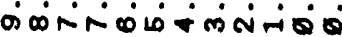

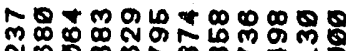
N

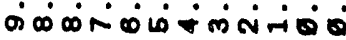

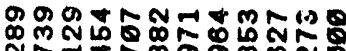

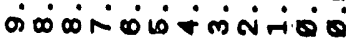

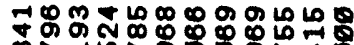

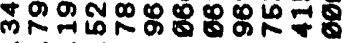

कம் ம்ம் ம்

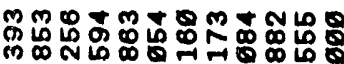

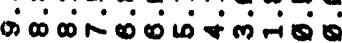

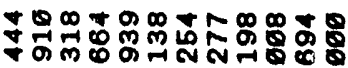

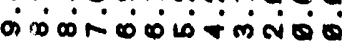

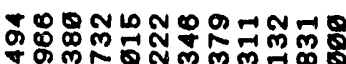

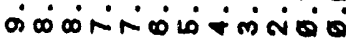

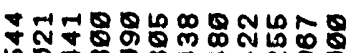

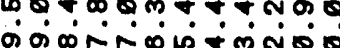

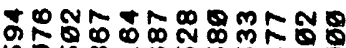

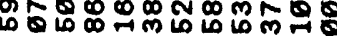

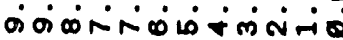

ำำำำำำำำ

-

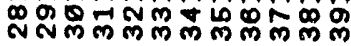

$\int_{0}^{\infty} \frac{0}{6} \frac{0}{6}$

बं००

$\operatorname{rin}$

$\infty \infty \infty$

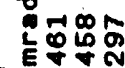

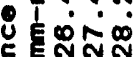 †े}

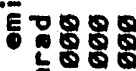

ธ

员

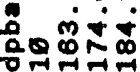

09000000000 岁

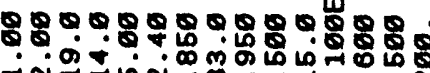
テNA I

| || || || | | | | | | | | | | |

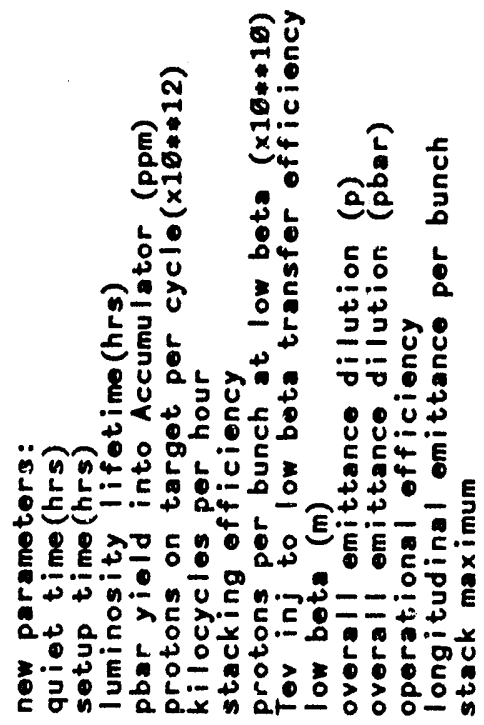

โ

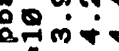

:

$2 \frac{0}{x}$

¿xx end

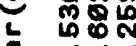

ํㅜㅇ

$\div \times 88$

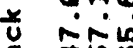

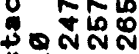

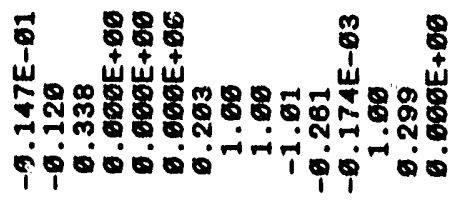

|| || || || | | | | | || | | | | |

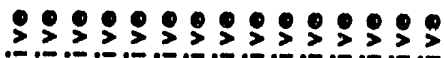

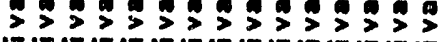

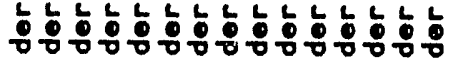

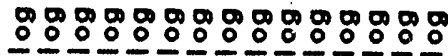

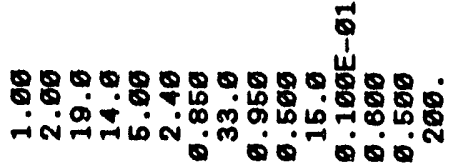

| || || || || || || || || || || || ||

o

ع

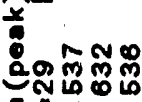

है

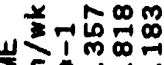

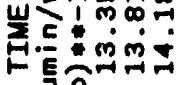

종을

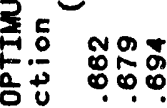

$\dot{0} 0 \dot{0}$

岌市

동는

बं०

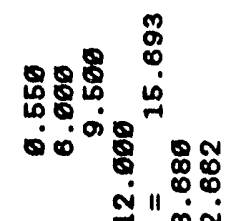

" ॥" ชัส

ㄷำ

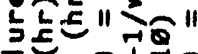

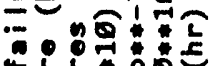

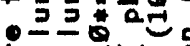

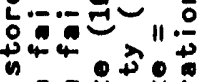

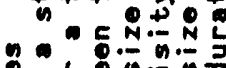

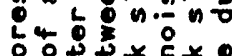
on $+8$

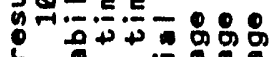
20

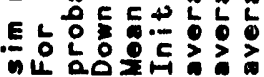



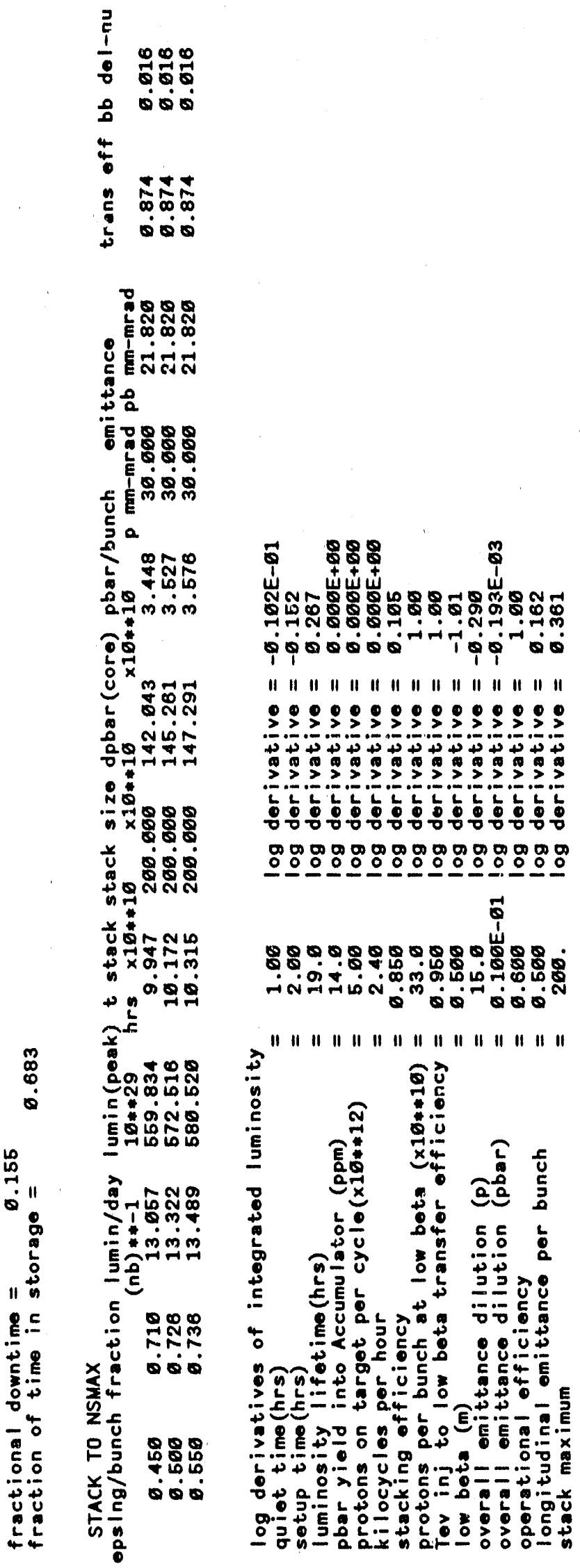

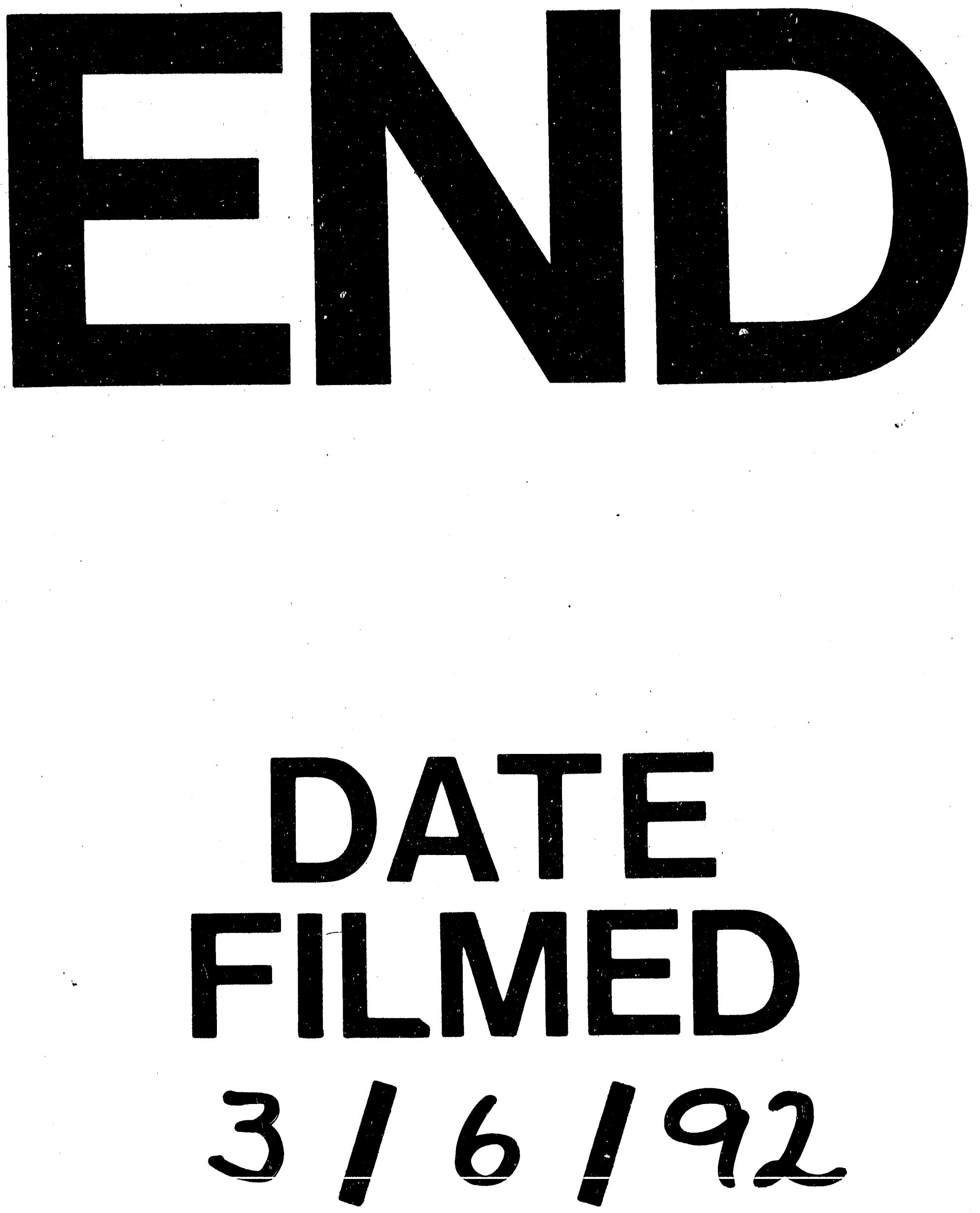
